\title{
Effects of Flow Parameters on the Characteristics of Biogas Flames in a Crossflow Air Stream
}

\author{
A. Harish ${ }^{(1)}$, V. Raghavan* ${ }^{*}$ \\ Thermodynamics and Combustion Engineering Laboratory, Department of Mechanical Engineering, Indian Institute of Technology \\ Madras, Chennai, India \\ Email: raghavan@iitm.ac.in
}

Received: 1 December 2021; Revised: 15 January 2022; Accepted: 25 January 2022

\begin{abstract}
This study presents the flame characteristics of laminar cross-flow non-premixed biogas-air flames established in a boundary layer using ANSYS Fluent. The validated numerical model is comprehensive enough to include variable thermo-physical properties, multi-component diffusion, short chemical kinetics mechanism, and optically thin approximation-based radiation model. Fuel is injected at a uniform velocity and the air is supplied perpendicular to it. Predicted and the in-house experimental biogas flames are qualitatively compared in terms of flame extents. The fuel flow rate has been varied from $0.02 \mathrm{~m} / \mathrm{s}$ to $0.04 \mathrm{~m} / \mathrm{s}$ to study the effects of power rating on the flame characteristics. At a given fuel flow rate, the airflow rate is incremented in steps to study the effects of forced convection on the characteristics and stability of the flames. Furthermore, the effects of the length of the flat plate upstream of the leading edge of the fuel injector plate on the flame anchoring location have been studied. The structure and characteristics of the reactive boundary layer are explained by using fields of temperature, velocity, mass fractions of major species, stoichiometric equivalence ratio, and Damköhler number. The reactive boundary layer fueled by methane is compared with that of biogas.
\end{abstract}

Keywords: biogas, reactive boundary layer, cross-flow, forced convection, multi-component mass diffusion, flame stability

\section{Introduction}

In comparison to premixed flames, diffusion flames operate over a wide range of air and fuel flow rates. Emissions in a non-premixed flame can be reduced with a proper burner design. Cross-flow burners are used in several industrial furnaces. In a cross-flow burner, air and fuel are injected perpendicular to each other, and in one such variation, fuel is injected through porous material to obtain a uniform velocity profile. In this case, a diffusion flame is formed over the fuel injector in a boundary layer formed above it. These flame characteristics depend on the characteristics of the boundary layer such as boundary layer thickness, fuel injection rate, airflow rate, and heat release-rate. Apart from forced convection, multi-component diffusion affects the characteristics and stability of these flames.

Numerous experimental and numerical investigations on laminar non-premixed boundary layer flames are reported in the literature. Emmons [1] was the first person to report a similarity solution for a laminar two-dimensional reactive

Copyright (C2022 V. Raghavan, et al.

DOI: https://doi.org/10.37256/est.3220221270

This is an open-access article distributed under a CC BY license

(Creative Commons Attribution 4.0 International License)

https://creativecommons.org/licenses/by/4.0/ 
boundary layer over a flat plate. Following this earliest work, there were several theoretical works reported on the analysis of buoyancy effects in the laminar flow over a flat plate [2], [3] and laminar diffusion flame over a flat plate [4]-[9]. Peters [10] numerically analyzed cross-flow non-premixed laminar flames of hydrogen and oxygen to study the near-equilibrium and non-equilibrium structure at different locations in the boundary layer. The model presented by Peters [10] supported the flame zone model proposed by Libby and Economos [11]. Acceleration of gas stream is observed [12], [13] closer to the flame zone in a laminar diffusion flame formed over a two-dimensional boundary layer over a flat plate. In a boundary layer flame over a liquid pool, the flame was said to be stable until the flame anchoring location did not shift downstream of the leading edge of the fuel wick due to an increase in free stream velocity of the air [13].

Experimental studies of a laminar boundary layer diffusion flame established that the flame extinction depends on oxygen availability, fuel concentration as well as on fuel injection velocity [14], the direction of injection has a significant effect on flame stability and flow field [15], local acceleration of the flow around the flame zone [12], [13], [15], [16] and presence of a boundary layer region (inertia dominated) and a plume region (buoyancy dominated) in normal gravity [17]. Numerical studies observed pressure perturbations in the flow field [18], dependency of flame anchoring location on the fuel reaction rate [19], presence of a premixed region at the leading edge of the flame [19], the validity of Emmons similarity solution only for a certain range of Re [20], presence of velocity overshoot in the flame zone in the upward fuel injection but not in the downward fuel injection [21].

Renewable fuels are expected to play a major role in the world energy scenario in near future. Biogas, one such renewable fuel, is produced from plant and animal wastes as a result of anaerobic fermentation of these organic substances [22], [23]. The biogas can be locally produced, safely stored in tanks, and used in the burners. The percentages of the major constituents of biogas depend on the source from which it is produced. Biogas mainly consists of $40 \%$ to $75 \%$ of methane and $15 \%$ to $60 \%$ of carbon dioxide [24]-[28].

In the case of the usage of fossil fuels such as natural gas and Liquefied Petroleum Gas (LPG), the instabilities associated with a cross-flow burner are primarily due to convective transport of fuel and oxidizer and to some extent due to the effects of the burner walls. However, when biogas is used, depending upon its carbon dioxide content, the thermal losses due to the presence of carbon dioxide add on to the instabilities. Therefore, the operating regime of a non-premixed burner should be assessed by using biogas in the required turn-down ratio.

A good amount of literature is available on flame characteristics of simulated biogas flames by adding carbon dioxide to methane and of pure biogas. The addition of carbon dioxide to fuel decreases the flame stability [29], [30], reduces the flame temperature [31]-[33], and laminar burning velocity [31], [32], [34], [35]. Apart from the above, adding carbon dioxide to fuel also leads to a decrease in nitric oxide emissions [31], [33], [36], [37] and soot formation [38].

It is clear from the previous studies that the presence of carbon dioxide in biogas has both positive effects (reduction in soot and $\mathrm{NO}_{\mathrm{x}}$ emissions) and negative effects (reduction in flame stability and higher volume flow rate of fuel for same power rating). It is also clear that there is no literature available on numerical investigation of laminar boundary layer biogas-air flames. Such study is important in understanding the detailed flow, species, and temperature fields in biogas flames, which are difficult to measure. Such a study would also reveal the stability aspects of the flames due to forced convective airflow. These form the motivation of the present study. Therefore, a detailed investigation of the structure and stability characteristics of biogas flames in a boundary layer configuration is carried out in this study. The flame characteristics of biogas and methane are also presented.

\section{Numerical methodology}

\subsection{Computational domain}

A 2D computational domain similar to the experimental setup of Hirano and Kanno [12] is used in the present study and is shown in Figure 1. The geometry is created using a design modeler available in ANSYS Workbench. In the experiments, the fuel inlet is an inert porous plate that is kept flush with the bottom wall of the combustion chamber. The porous plate ensures uniform injection of fuel into the combustion chamber. The combustion chamber itself is a part of a wind tunnel, where the uniform airflow of required free stream velocity can be established in the horizontal direction. This is a basic geometry that produces a cross-flow diffusion flame. 
The fuel is supplied at a uniform velocity over a length of $120 \mathrm{~mm}$ as indicated in Figure 1 . The extension of the domain after the fuel injector is $20 \mathrm{~mm}$. Before the leading edge of the fuel inlet, the domain extent in the horizontal direction (L) is varied from $20 \mathrm{~mm}$ to $150 \mathrm{~mm}$. Air flows with a uniform velocity into the domain from the left boundary and the hot products of combustion leave the domain through the right boundary. Standard air, with a composition of $21 \%$ oxygen and $79 \%$ nitrogen by volume, is considered in the numerical simulations.

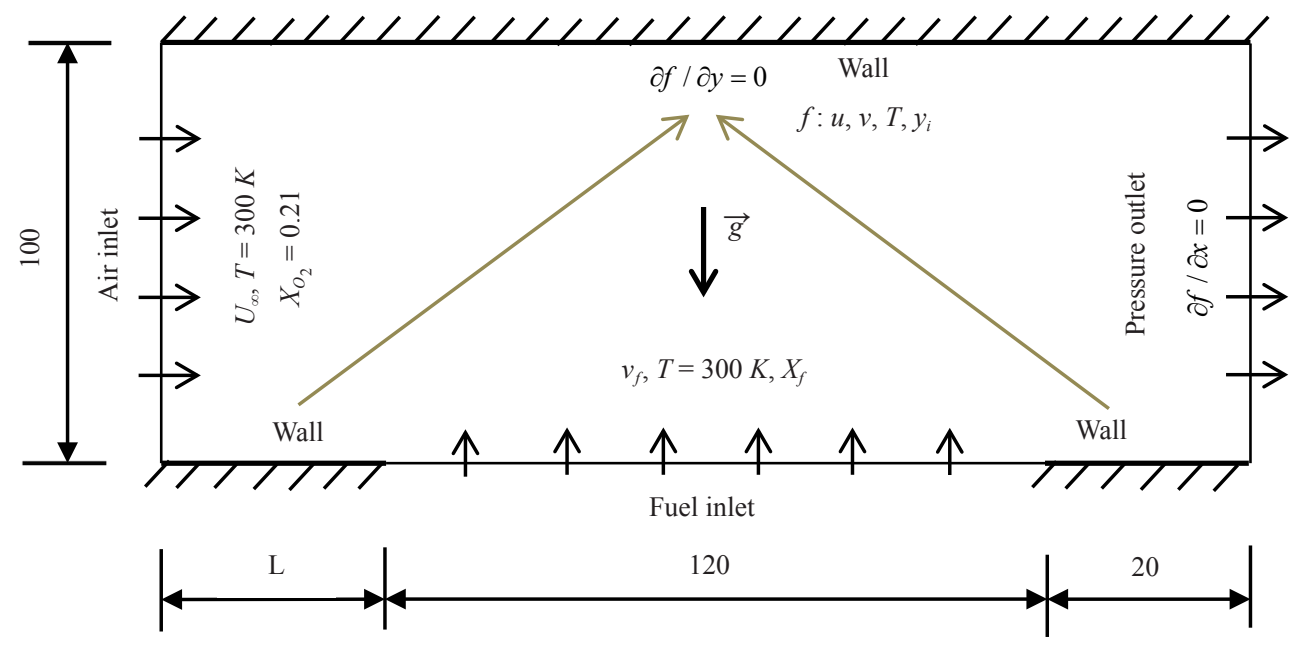

Figure 1. Computational domain (all dimensions are in $\mathrm{mm}$ )

\subsection{Boundary conditions}

The boundary conditions used in the present study are presented in Table 1.

Table 1. Imposed boundary conditions

\begin{tabular}{|c|c|c|}
\hline Boundary name & Description & Boundary values \\
\hline Air inlet & $\begin{array}{l}\text { Air at uniform velocity is injected. } \\
\text { For a given fuel velocity, } \\
\text { air velocity is incremented in steps till blow-off. }\end{array}$ & $\begin{array}{c}T=300 \mathrm{~K}, U=0.2 \mathrm{~m} / \mathrm{s} \text { to } 1 \mathrm{~m} / \mathrm{s}, V=0 \mathrm{~m} / \mathrm{s} \\
Y_{\mathrm{O}_{2}}=0.21, Y_{N_{2}}=0.79\end{array}$ \\
\hline Fuel inlet & Fuel is injected at uniform velocity. & $\begin{array}{c}T=300 \mathrm{~K}, U=0 \mathrm{~m} / \mathrm{s}, V=\text { required value. } \\
\text { When the fuel is } \\
\text { Biogas- } X_{\mathrm{CH}_{4}}=0.55, X_{\mathrm{CO}_{2}}=0.45 \\
\text { Methane, } Y_{\mathrm{CH}_{4}}=1\end{array}$ \\
\hline Wall & All the walls are adiabatic in nature. & $U=V=0, \partial f / \partial n=0$ \\
\hline Pressure outlet & $\begin{array}{l}\text { Combustion products leave this boundary. } \\
\text { In case of an adverse local pressure gradient, } \\
\text { air enters the computational } \\
\text { domain through this boundary. }\end{array}$ & $\begin{array}{l}\text { In the case of favorable pressure gradient, } \\
\text { the variables are extrapolated from the } \\
\text { adjacent interior cells and } \partial f / \partial x=0 \text {. } \\
\text { In case of adverse pressure gradient, } \\
\text { air enters the domain with } X_{\mathrm{O}_{2}}=0.232 \text {, } \\
\qquad X_{N_{2}}=0.768 \text { at } T=300 \mathrm{~K}\end{array}$ \\
\hline
\end{tabular}

In Table 1, $U$ is x-velocity, $V$ is y-velocity, $Y_{\mathrm{O}_{2}}$ is the mole fraction of oxygen, $Y_{N_{2}}$ is the mole fraction of nitrogen, $X_{\mathrm{CH}_{4}}$ is the mole fraction of methane, $X_{\mathrm{CO}_{2}}$ is the mole fraction of carbon dioxide, and $f$ is a variable that includes $U, V, T$, 
and $Y$ (mass fraction).

\subsection{Models and discretization schemes}

Steady-state conservation equations are solved in a segregated manner using ANSYS Fluent 15.0. Semi-Implicit Method for Pressure Linked Equations (SIMPLE) algorithm is used to handle pressure velocity coupling. The gradientbased least-square cell method is used for spatial discretization of pressure. The second-order upwind scheme is employed for the spatial discretization of convective terms. Mixing and transport of each species are solved by the species transport model considering the convection, diffusion, and reaction rates of each species. Full multicomponent diffusion and thermal diffusion are considered for calculating species diffusional velocity. The diffusion energy source sub-model is used to include the transport of enthalpy by the diffusing species. Temperature and concentrationdependent thermo-physical properties are used. The overall chemical kinetics mechanism for methane combustion consists of $\mathrm{C}_{1}$ and $\mathrm{C}_{2}$ carbon species. Finite rate chemistry constituted by multiple elementary reactions is used for calculating the volumetric reaction rates. The laminar finite rate model, which uses Arrhenius type rate equations, is employed to find the net reaction rate of a species. In addition, a stiff chemistry solver is used. A short chemical kinetic mechanism, which has 25 species and 121 elementary reactions, is used. This kinetic mechanism is obtained after removing the higher hydrocarbons above $\mathrm{C}_{2}$ and the species containing nitrogen atom except for $\mathrm{N}_{2}$, and the associated elementary reactions, from GRI 2.11 mechanism, originally developed for methane combustion. The species present in the mechanism are $\mathrm{H}_{2}, \mathrm{H}, \mathrm{O}, \mathrm{O}_{2}, \mathrm{OH}, \mathrm{H}_{2} \mathrm{O}, \mathrm{HO}_{2}, \mathrm{H}_{2} \mathrm{O}_{2}, \mathrm{CH}, \mathrm{CH}_{2}, \mathrm{CH}_{3}, \mathrm{CH}_{4}, \mathrm{CO}, \mathrm{CO}_{2}, \mathrm{HCO}, \mathrm{CH}_{2} \mathrm{O}, \mathrm{CH}_{3} \mathrm{O}, \mathrm{C}_{2} \mathrm{H}, \mathrm{C}_{2} \mathrm{H}_{2}$, $\mathrm{C}_{2} \mathrm{H}_{3}, \mathrm{C}_{2} \mathrm{H}_{4}, \mathrm{C}_{2} \mathrm{H}_{5}, \mathrm{C}_{2} \mathrm{H}_{6}, \mathrm{HCCO}$, and $\mathrm{N}_{2}$.

\subsection{Radiation sub-model}

In the present work, soot emissions are not significant in the atmospheric pressure combustion of methane and biogas. However, thermal radiation absorption by participating species such as $\mathrm{CO}_{2}, \mathrm{CO}, \mathrm{H}_{2} \mathrm{O}$, and $\mathrm{CH}_{4}$ is important. Therefore, a radiation sub-model that has been proposed by Barlow et al. [39] which depends on optically thin approximation, is employed. Using Planck's absorption coefficient for the participating species, the thermal energy loss due to radiation is calculated as a thermal sink term. This radiation heat loss term is implemented using a User Defined Function (UDF) in Fluent.

\subsection{Solution procedure}

A case with lower air velocity is chosen to establish a stable flame that anchors in the plate region upstream of the fuel injector. All the boundary conditions are specified based on the case under consideration. Steady-state governing equations are solved without the volumetric reactions for around 2,000 iterations. At this stage, the flow is sufficiently established and a flammable mixture is formed. A high-temperature patch of 1,800 K is applied to a selected flammable region near the leading edge of the fuel inlet. The volumetric reactions are switched on and the reactive flow is solved in a steady-state manner. For all the cases, the convergence check is made after 60,000 iterations. The solution is said to be converged if the normalized continuity residual value is below $1 \times 10^{-3}$ and the energy residual value is below $1 \times 10^{-6}$. The mass imbalance is always below $1 \%$, and it is calculated as the ratio of net mass efflux divided by the minimum input mass flow rate into the domain. The steadiness of the converged solution is also checked by plotting profiles of variables such as temperature, velocity, and species mass fraction at several x-locations at the end of several iterations.

\subsection{Choice of the mesh and validation}

The meshing scheme followed in this study is based on the systematic grid-independent scheme reported in [21]. A structured mesh with 64,000 quadrilateral cells is used in the present simulations. Similarly, numerical results have been thoroughly validated for methane-air cross flow flames by Gopalakrishnan and Raghavan [21] using the experimental data from the literature [12], [15], [19]. In this study, all the model parameters are kept the same as in [21] and similar validation results have been obtained for methane-air flames (Appendix A). Since experimental results in terms of 
temperature and velocity measurements are not available for biogas flames, quantitative validation of the numerical results for biogas flames has been carried out in this study.

Harish et al. [40] used an in-house experimental setup to reveal stability regimes of biogas-air flames without and with obstacles. As opposed to the domain shown in Figure 1, the setup has a fuel injector with a length of $70 \mathrm{~mm}$ and adiabatic walls with lengths of $150 \mathrm{~mm}$ and $80 \mathrm{~mm}$ in the upstream and downstream of the fuel injector, respectively. However, this setup does not have access to instrumentation for measuring temperature and species concentration [40].

To provide a qualitative comparison between the predicted results and experimental biogas flame, an experiment is conducted in the in-house experimental setup. Using the high-definition flame photograph of a typical boundary layer flame of biogas and air, the visible flame extents have been compared with predicted contours of OH. A case with biogas injection velocity of $0.02 \mathrm{~m} / \mathrm{s}$ and air velocity of $0.4 \mathrm{~m} / \mathrm{s}$ has been considered. The direct flame photograph and predicted $\mathrm{OH}$ contours are shown in Figure 2. It is clear from Figure 2 that the numerical model can predict the flame extents in terms of $\mathrm{OH}$ field, close to that of the visible flame. The flame anchoring location has also been captured well.
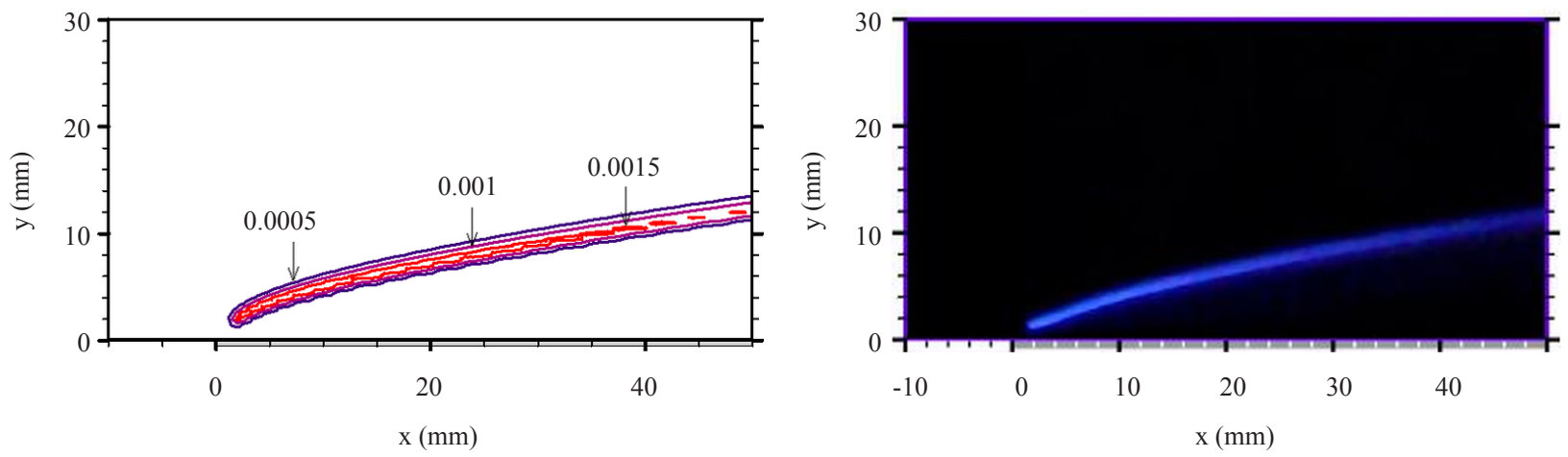

Figure 2. Qualitative comparison of predicted contours of mass fraction of $\mathrm{OH}$ (left) against the direct flame photograph (right)

\section{Results and discussion}

\subsection{Temperature, velocity, species, and reaction fields}

Temperature, velocity, species, and reaction fields are much difficult to measure. With the validated numerical model, these fields can be predicted with required accuracy and can be analyzed to derive a useful physical understanding of the flames. First, a case where the distance between the leading edge of the fuel injector and the inlet of the air stream (L) is $70 \mathrm{~mm}$ is considered (Figure 1). A fuel velocity of $0.04 \mathrm{~m} / \mathrm{s}$ and an air velocity of $0.4 \mathrm{~m} / \mathrm{s}$ are selected. Figure 3 presents the features of a flame that is stabilized in the plate region upstream of the leading edge of the fuel injector. The isotherms along with a contour line of stoichiometric $(\phi=1)$ equivalence ratio (shown as a dashed line), are presented on the left side of Figure 3(a). The stoichiometric equivalence ratio line is calculated as $Y_{\mathrm{CH}_{4}}-Y_{\mathrm{O}_{2}} / v$ $=0$, where $Y$ is mass fraction and $v$ is mass of oxygen required to burn one $\mathrm{kg}$ of methane $(v=4)$. The high-temperature isotherms extend beyond the leading edge of the fuel injector into the upstream plate region, thus forming an anchoring point in that region. This has been termed plate stabilized flames. The stoichiometric equivalence ratio contour line is seen close to the maximum temperature $(1,820 \mathrm{~K})$ isotherm. To the right of this, contours lines of oxygen mass fraction along with vectors of the mixture velocity are shown. The flow is accelerated as its crosses the flame zone. This is called velocity overshoot observed in a reactive flow field, where the local velocity magnitude exceeds the free stream value ( 0.4 $\mathrm{m} / \mathrm{s}$ ). Oxygen penetration from the top towards the flame zone is also clearly observed through the oxygen contours.

The contour line of oxygen mass fraction value of around 0.02 is seen to coincide with the stoichiometric equivalence ratio line. Contour lines of mass fractions of $\mathrm{OH}$ and $\mathrm{CO}$, two important species contributing to the heat release, and flame anchoring are shown in the left and right sides of Figure 3(b). It is clear that the CO is distributed over a wide area, whereas $\mathrm{OH}$ distribution occurs in a relatively thin zone. Both $\mathrm{CO}$ and $\mathrm{OH}$ are seen to be present to the left of the leading edge of the fuel injector. Further, the consumption of $\mathrm{CO}$ is engulfed by the $\mathrm{OH}$ contour lines of 
0.001. This is because $\mathrm{OH}$ contributes to $\mathrm{CO}$ oxidation as well as to the formation of water vapor. Damköhler number $(\mathrm{Da})$, which is a ratio of flow time to the chemical reaction time, is an important parameter that indicates flame stability.
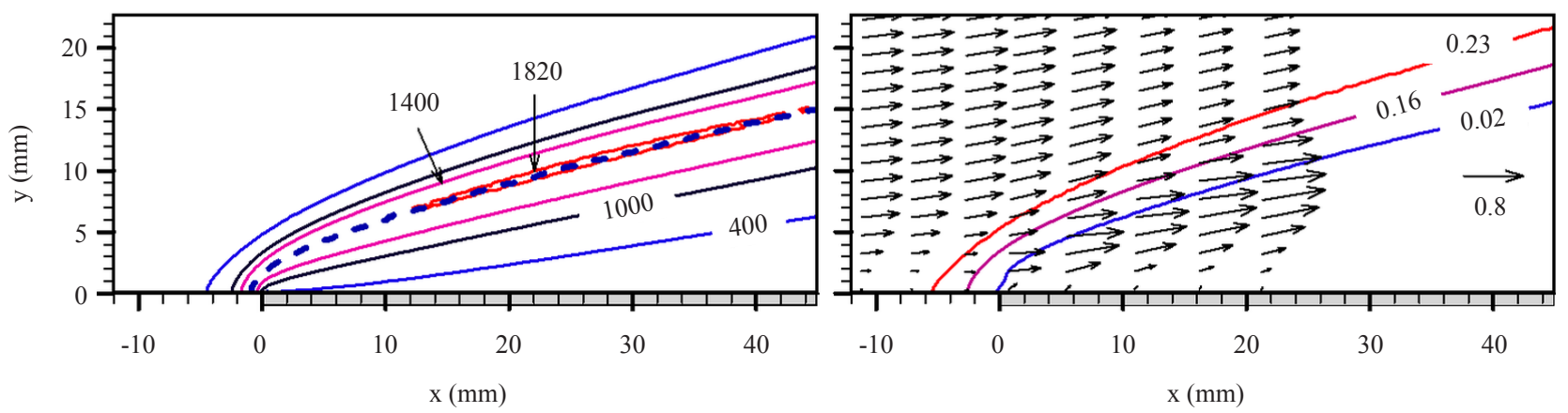

(a)
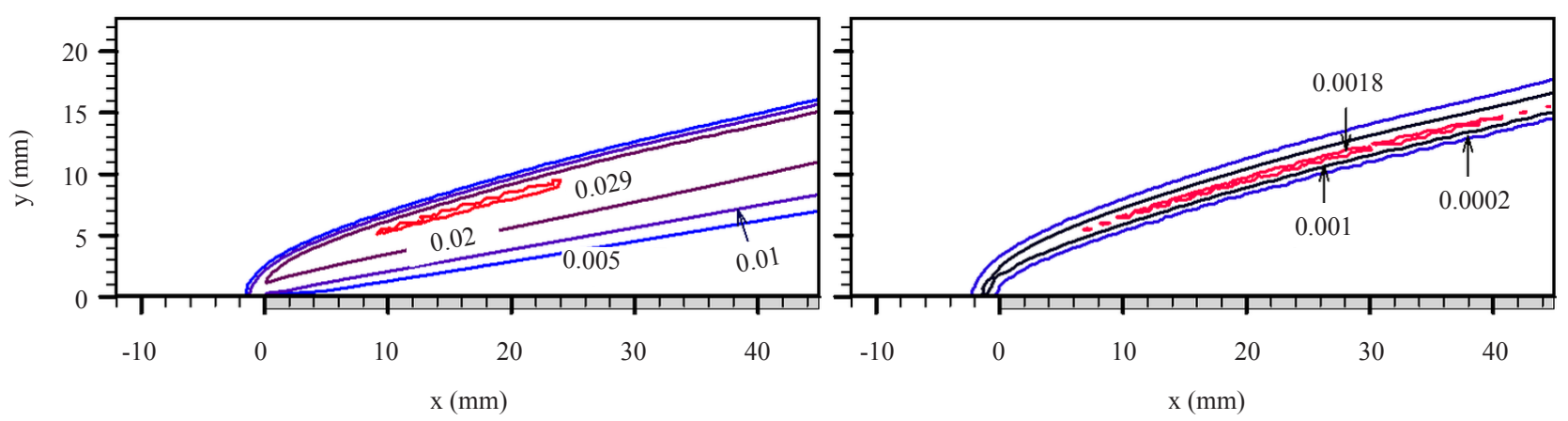

(b)

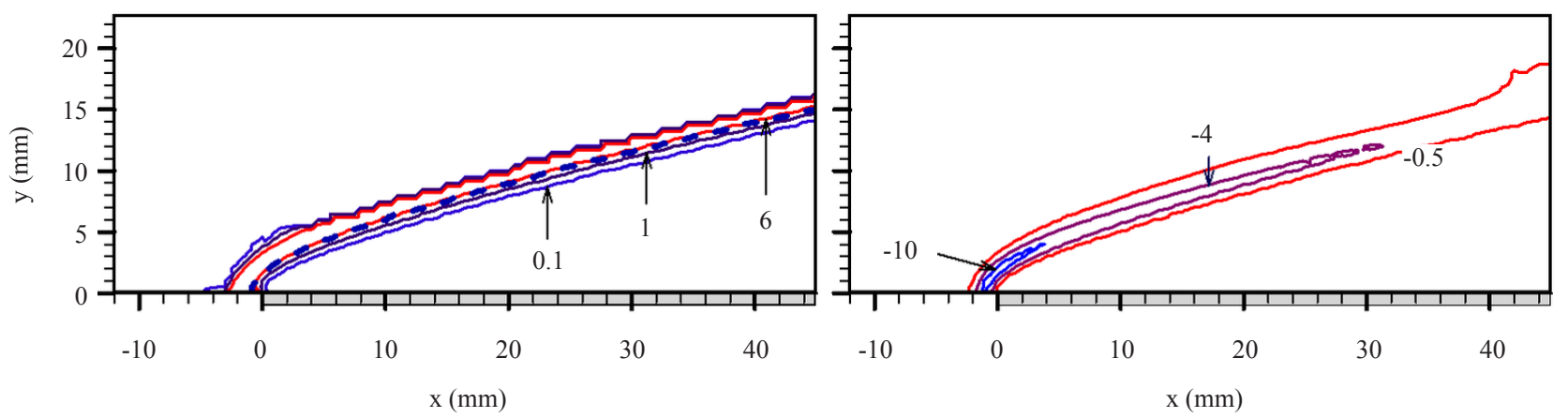

(c)

Figure 3. (a) Isotherms with contour line of stoichiometric equivalence ratio (left), vectors of mixture velocity and contours of mass fraction of $\mathrm{O}_{2}$ (right),

(b) contours of mass fractions of $\mathrm{CO}$ (left) and $\mathrm{OH}$ (right), (c) contours of Damköhler number (left) and $\mathrm{NRR}$ of $\mathrm{O}_{2}$ (right) for the case with $\mathrm{L}=70 \mathrm{~mm}$, with a fuel velocity of $0.04 \mathrm{~m} / \mathrm{s}$ and air velocity of $0.4 \mathrm{~m} / \mathrm{s}$

In the present work, local Da is calculated in each cell using a UDF similar to the method reported by Shijin et al. [41]. In a cell, the flow time is computed as the ratio of the length of the cell in the x-direction to the diffusion velocity methane in that cell. Similarly, the reaction time is calculated as the ratio of the density of methane to the Net Reaction Rate (NRR) of methane in that cell. The diffusion velocity of methane $\left(\overrightarrow{v_{C_{4}}}\right)$ in a given cell, due to ordinary and thermal diffusion processes, is calculated as,

$$
\overrightarrow{v_{C H_{4}}}=\vec{V}-\left[\left(D_{C_{4, m}} \times \overrightarrow{\nabla Y_{C H_{4}}} / Y_{C_{4}}\right)+\left(D_{T, C H_{4}} \times \overrightarrow{\nabla T}\right) /\left(\rho_{C_{4}} \times T\right)\right]
$$


Here, $\vec{V}$ is the mixture velocity, $D_{C H_{4, m}}$ and $D_{T, C H_{4}}$ are mass and thermal diffusion coefficients of $C H_{4}, T$ is temperature, $Y_{\mathrm{CH}_{4}}$ is the mass fraction of methane, $\rho_{\mathrm{CH}_{4}}$ is the density of methane in the cell.

A flame zone forms if $\mathrm{Da} \geq 1$, where there is a balance between the flow and the chemical reaction times. The left side of Figure 3(c) shows the contour lines of Da. It is seen that the contour line of $\mathrm{Da}=6$ is closer to the stoichiometric equivalence ratio line. Contours of Net Reaction Rate (NRR) of oxygen are shown in the right side of Figure 3(c). The oxygen consumption occurs right from the high-temperature region upstream of the leading edge of the fuel injector.

The NRR of methane along with the diffusion velocity of methane (Equation 1) is shown in the left side of Figure 4. The diffusion velocity of methane is calculated as a sum of concentration gradient-based (ordinary) diffusion and that due to temperature gradient (Soret diffusion).
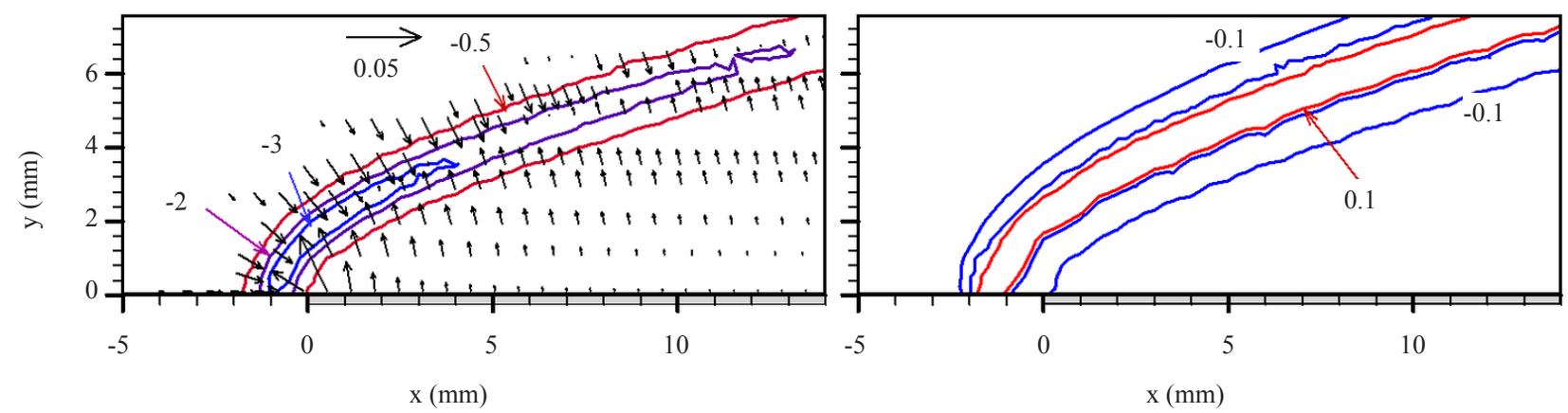

Figure 4. Contours of $\mathrm{NRR}$ of $\mathrm{CH}_{4}$ with vectors of diffusion velocity of $\mathrm{CH}_{4}$ (left) and contours of NRR of $\mathrm{OH}$ (right) for the case with $\mathrm{L}=70 \mathrm{~mm}$, with a fuel velocity of $0.04 \mathrm{~m} / \mathrm{s}$ and air velocity of $0.4 \mathrm{~m} / \mathrm{s}$

The Soret diffusion can be quite stronger depending upon the temperature gradient. Methane coming out of the fuel injector (inner zone) diffuses towards the flame zone. The thermal diffusion coefficient is generally negative for lighter species such as methane. Thermal diffusion for methane is seen to occur from low to high temperatures. The diffusion vectors shown in the outer zone (the region between the flame and the ambient) indicate that the methane formed in the outer zone (near to the flame zone) diffuses into the flame zone. The consumption of methane is very rapid near the leading edge of the fuel injector, where fuel and fresh oxygen mix to react. The contours of the net reaction rate of $\mathrm{OH}$ are shown in the right side of Figure 4. The consumption of $\mathrm{OH}$ occurs in two zones indicated by the negative values. In the inner zone, it reacts to form water and in the outer zone, it reacts with $\mathrm{CO}$ to form $\mathrm{CO}_{2}$. It is known that the reaction of $\mathrm{CO}$ and $\mathrm{OH}$ contributes to heat release.

\subsection{Effect of air velocity}

Here the case with $\mathrm{L}=70 \mathrm{~mm}$ is chosen and the effect of air velocity is studied. The fuel velocity is kept constant at $0.04 \mathrm{~m} / \mathrm{s}$ and the air velocity is varied from $0.4 \mathrm{~m} / \mathrm{s}$ to $0.9 \mathrm{~m} / \mathrm{s}$. Figure 5 presents the isotherms along with the contour line of $\phi=1$ (left) and oxygen contours with vectors of mixture velocity (right). At a low air velocity of $0.4 \mathrm{~m} / \mathrm{s}$ (Figure 5(a)), a plate stabilized flame is observed as discussed in Figure 3.

As the air velocity is increased to $0.7 \mathrm{~m} / \mathrm{s}$, the flame anchoring point moves from upstream of the leading edge of the fuel injector to a location just downstream of the leading edge of the fuel injector. This is shown by the slight movement of the isotherms towards the right (Figure 5(b)) and nearly ambient temperature prevails just upstream of the leading edge of the fuel injector. However, in this case, the contour line of $\phi=1$ (Figure 5(b), left) is quite similar to the case with an air velocity of $0.4 \mathrm{~m} / \mathrm{s}$. This indicates that the stoichiometric mixing of fuel and oxygen happens near the leading edge of the fuel injector as in the previous case. However, there is a shortage of flow residence time so that the flame is unable to anchor to the plate as in the lower air velocity case. The contours of oxygen mass fraction (Figure 5(b), right) clearly show the movement of oxygen towards the fuel injection zone as a result of increased convection. Velocity vectors in a similar manner indicate the velocity overshoot across the flame with a slightly higher magnitude. 

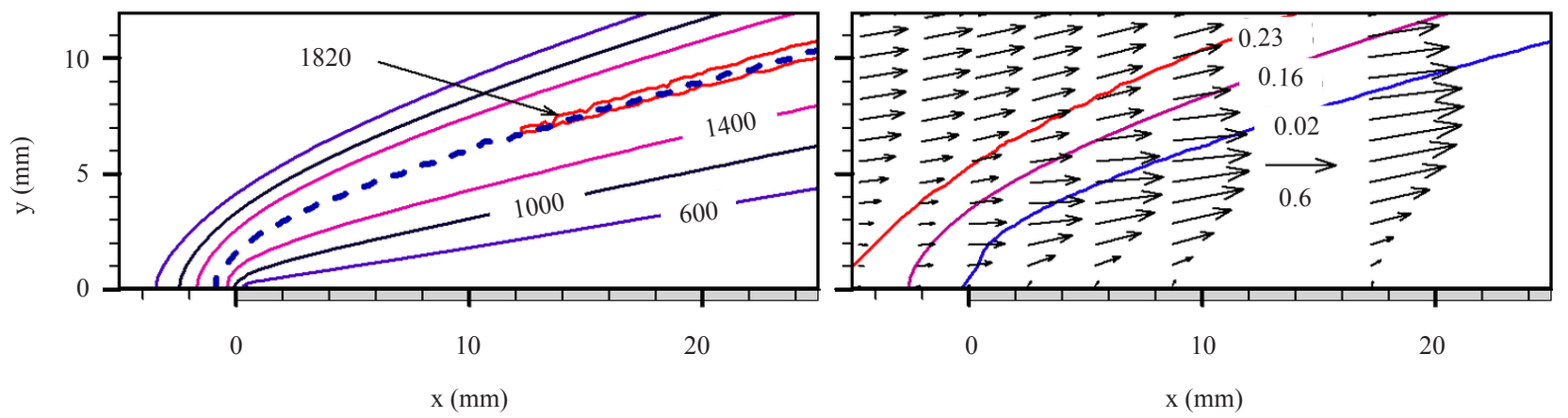

(a)
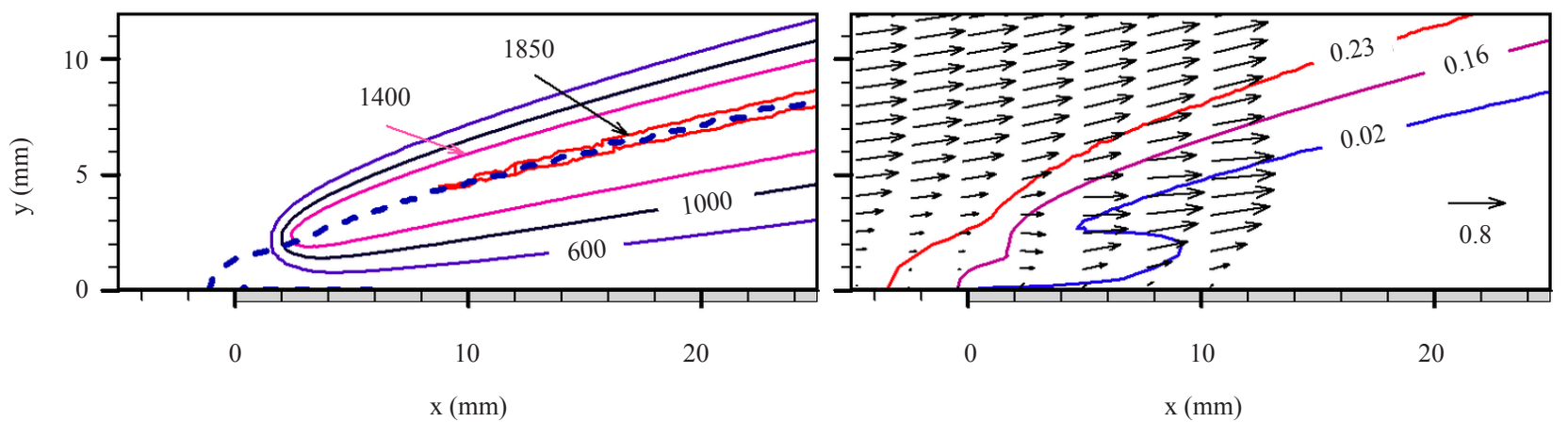

(b)
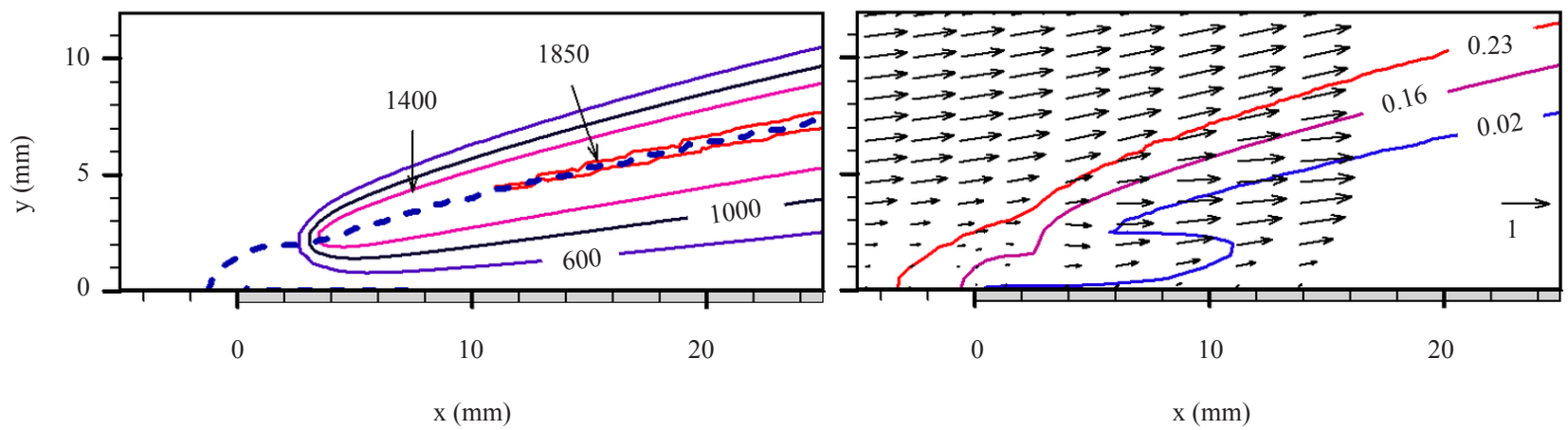

(c)

Figure 5. Contours of temperature (left) and mass fraction of oxygen along with velocity vectors (right) for the case of $\mathrm{L}=70 \mathrm{~mm}$ with a fuel velocity of $0.04 \mathrm{~m} / \mathrm{s}$ and air velocity of (a) $0.4 \mathrm{~m} / \mathrm{s}$, (b) $0.7 \mathrm{~m} / \mathrm{s}$ and (c) $0.9 \mathrm{~m} / \mathrm{s}$

The $\mathrm{OH}$ and $\mathrm{CO}$ fields are shown in the left side of Figure 6. These clearly show the flame movement due to increased cross-flow convection. In the plate stabilized case (Figure 6(a)), the contour lines of $\mathrm{CO}$ and $\mathrm{OH}$ have a zero gradient at the plate region before the fuel injector, if the contours extend to the plate surface as in the attached flame (Figure 6(a)). At the higher air velocity, the flame is not seen to anchor anywhere. This flame has characteristics of a flame with a partially premixed kernel initially and that grows as a non-premixed flame at farther x-locations. As the air velocity is increased, the flame stand-off is seen to decrease. The flame stand-off distance is defined as the normal distance of the flame zone (taken as the middle of the $\mathrm{OH}$ zone) measured from the fuel injector surface. At a further higher air velocity of $0.9 \mathrm{~m} / \mathrm{s}$, the flame is observed to move slightly downstream, its stand-off further decreases, but the overall characteristics are almost similar to the case with an air velocity of $0.7 \mathrm{~m} / \mathrm{s}$. As mentioned earlier, OH consumption contributes to $\mathrm{CO}$ conversion to $\mathrm{CO}_{2}$ and the formation of $\mathrm{H}_{2} \mathrm{O}$. It is clear from the left side of Figure 6 that $\mathrm{CO}$ is consumed in the region of $\mathrm{OH}$ shown by its contour line with a value of 0.001 and $\mathrm{H}_{2} \mathrm{O}$ is formed just below 
that as shown in the right side of Figure 6.

Figure 7 presents the contours of $\mathrm{Da}$ at three air velocities, along with the contour line of $\phi=1$ on its left side. As seen earlier, it is clear that the $\phi=1$ line covers the fuel injector and extends just upstream of its leading edge. If sufficient chemical time is available, then reaction zones could have been established around the locations indicated by $\phi=1$ line. However, due to insufficient flow residence time at higher air velocities, the reaction zone moves away from the leading edge of the fuel injector. This is clearly shown in Da contours. The region delineated by Da $=6$ line falls much closer to the high-temperature zone (about 1,830 K) indicating that the chemical reaction is at the peak at those locations. The contour line of $\phi=1$ indicates that some amount of premixing happens near the leading edge of the fuel injector. Thus, the flame initiates as a partially premixed flame and extends downstream as a diffusion flame following the $\phi=1$ contour line.

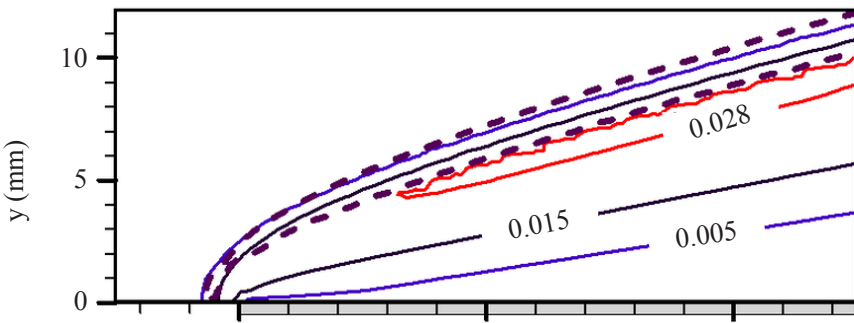

0

10

$\mathrm{X}(\mathrm{mm})$

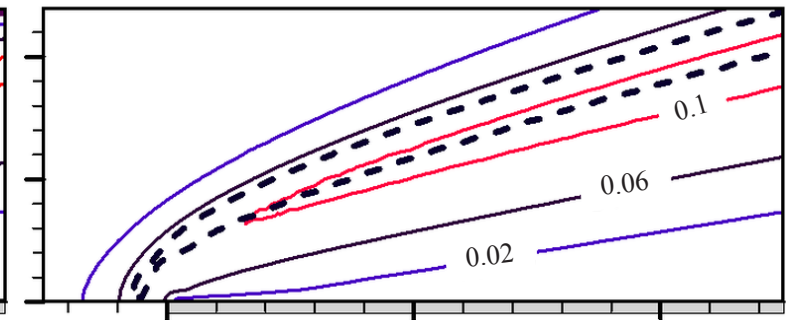

0

10

$\mathrm{X}(\mathrm{mm})$

(a)

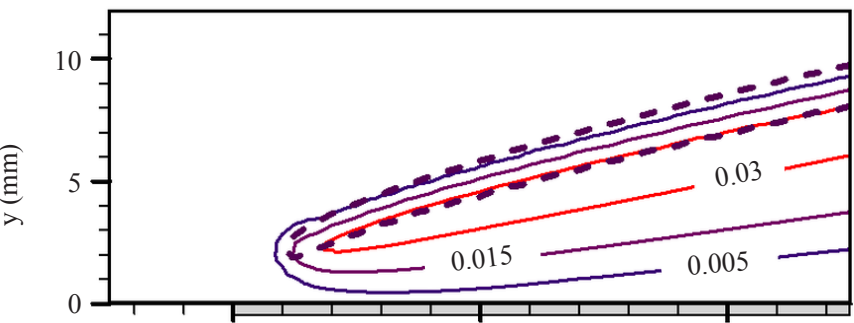

0

10

$\mathrm{x}(\mathrm{mm})$

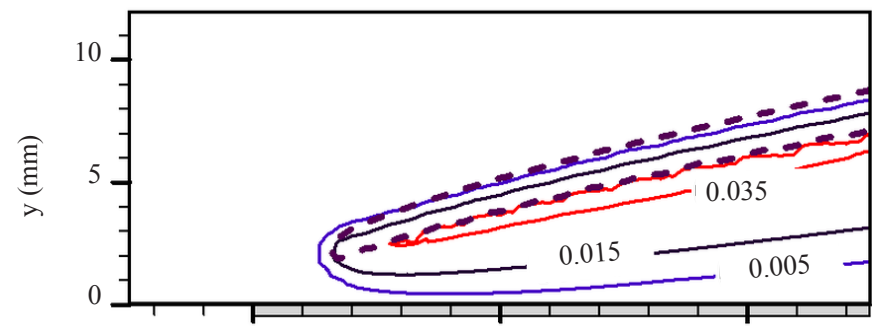

10

$\mathrm{x}(\mathrm{mm})$

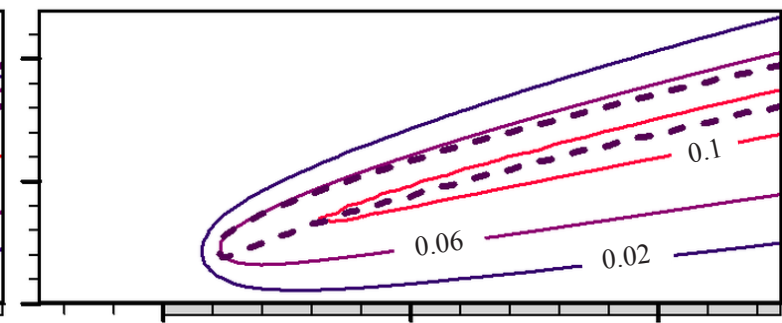

0

10

20

$\mathrm{x}(\mathrm{mm})$

(b)

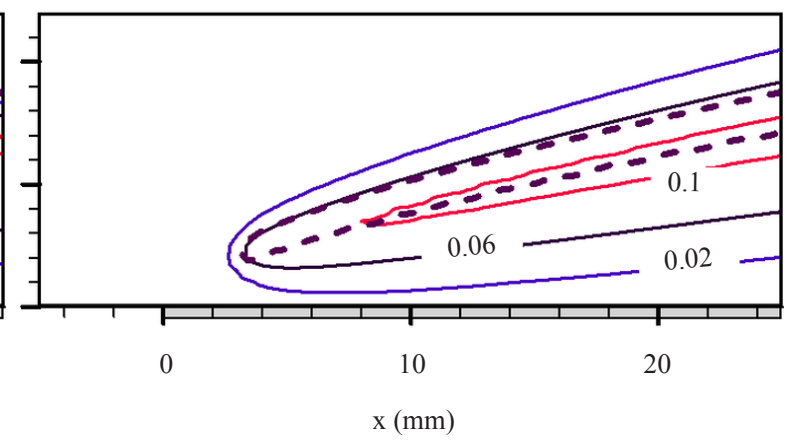

(c)

Figure 6. Contours of mass fraction of $\mathrm{CO}$ (left) and mass fraction of $\mathrm{H}_{2} \mathrm{O}$ (right) along with contour line (dashed) of $\mathrm{OH}$ with a value of 0.001 for the case of $L=70 \mathrm{~mm}$ with a fuel velocity of $0.04 \mathrm{~m} / \mathrm{s}$ and air velocity of (a) $0.4 \mathrm{~m} / \mathrm{s}$, (b) $0.7 \mathrm{~m} / \mathrm{s}$ and (c) $0.9 \mathrm{~m} / \mathrm{s}$ 
Figure 7 also presents the contours of net reaction rates of $\mathrm{CH}_{4}$ along with diffusion velocity vectors of methane on its right side. It is apparent that for higher velocities of $0.7 \mathrm{~m} / \mathrm{s}$ and $0.9 \mathrm{~m} / \mathrm{s}$, the reaction zone has moved downstream of the leading edge of the fuel injector. Even though fuel and oxygen are available at stoichiometric proportions, due to lower residence time, reaction zones form away from the leading edge of the fuel injector, where the chemical time matches the flow time $(\mathrm{Da}=1)$. The diffusion velocity of methane shows that at higher air velocities, diffusion of methane occurs only in the region where a flame zone has been formed. This also clearly shows that the flame sustains as a diffusion-controlled flame after the initial premixing. Further, the magnitude of diffusion velocity is seen to increase with an increase in the air velocity, as a result of increased diffusion of oxygen due to its higher feed rate.
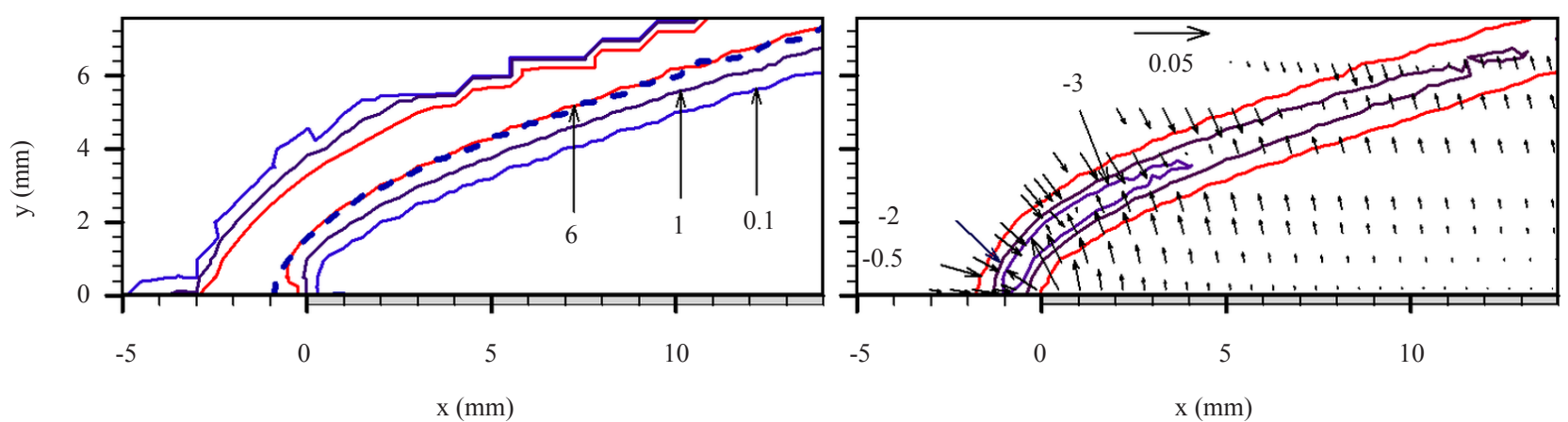

(a)
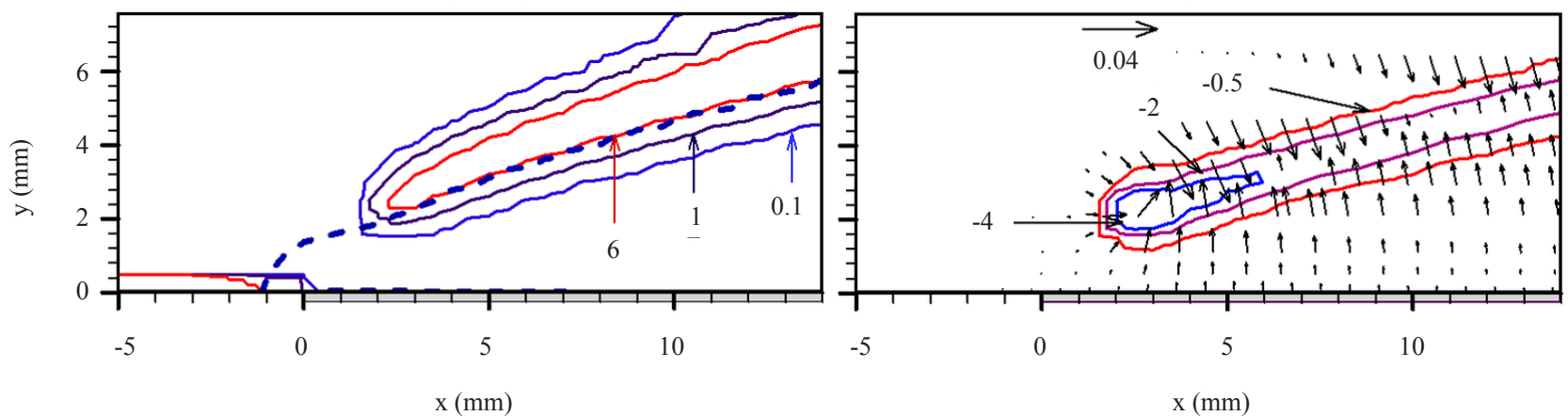

(b)
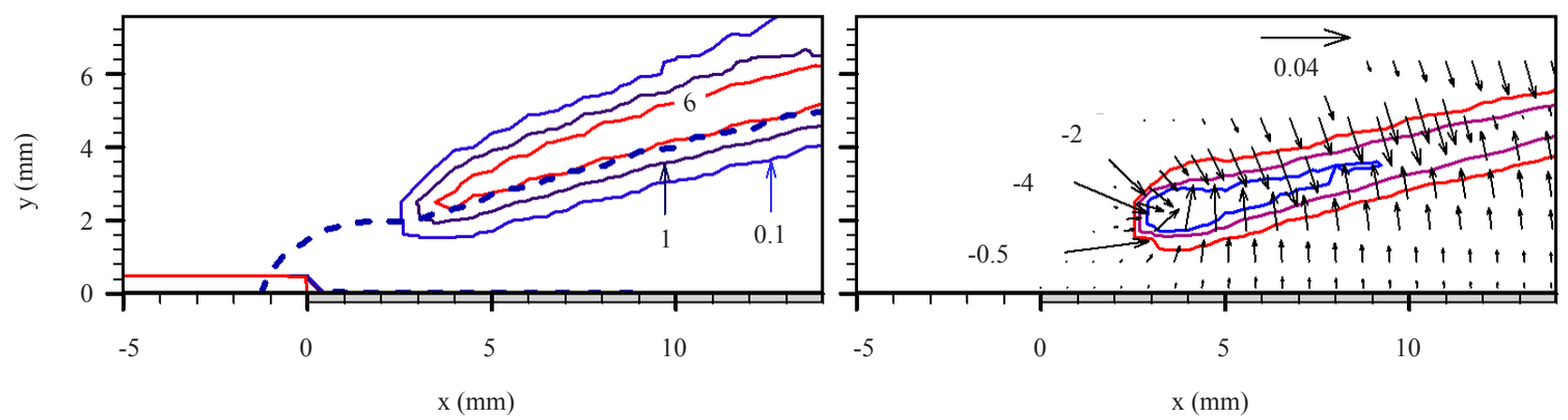

(c)

Figure 7. Contours of Da along with $\phi=1$ line (dashed line) (left) and contours of NRR of $\mathrm{CH}_{4}$ along with vectors of methane diffusion velocity (right), for fuel velocity of $0.04 \mathrm{~m} / \mathrm{s}$, air velocity of (a) $0.4 \mathrm{~m} / \mathrm{s}$, (b) $0.7 \mathrm{~m} / \mathrm{s}$ and (c) $0.9 \mathrm{~m} / \mathrm{s}$ (right) and $\mathrm{L}=70 \mathrm{~mm}$ 


\subsection{Effect of fuel velocity}

Figure 8 presents the effect of fuel velocity on flame characteristics. Keeping the air velocity at $0.4 \mathrm{~m} / \mathrm{s}$, the fuel velocity is varied in the range of $0.02 \mathrm{~m} / \mathrm{s}$ to $0.04 \mathrm{~m} / \mathrm{s}$. As the fuel velocity is increased, the flame comes closer to the leading edge and attaches to the plate. Isotherms with the contour line of $\phi=1$ shown in the left side of Figure 8, clearly indicate the movement of the flame as the fuel velocity is increased. It is also clear that the contour line of $\phi=1$ starts just upstream of the leading edge of the fuel injector, irrespective of the location of the flame zone. An increase in the momentum of the fuel stream at higher velocities forms the reason for these trends. This becomes clear from the oxygen contours and mixture velocity vectors shown on the right side of Figure 8.

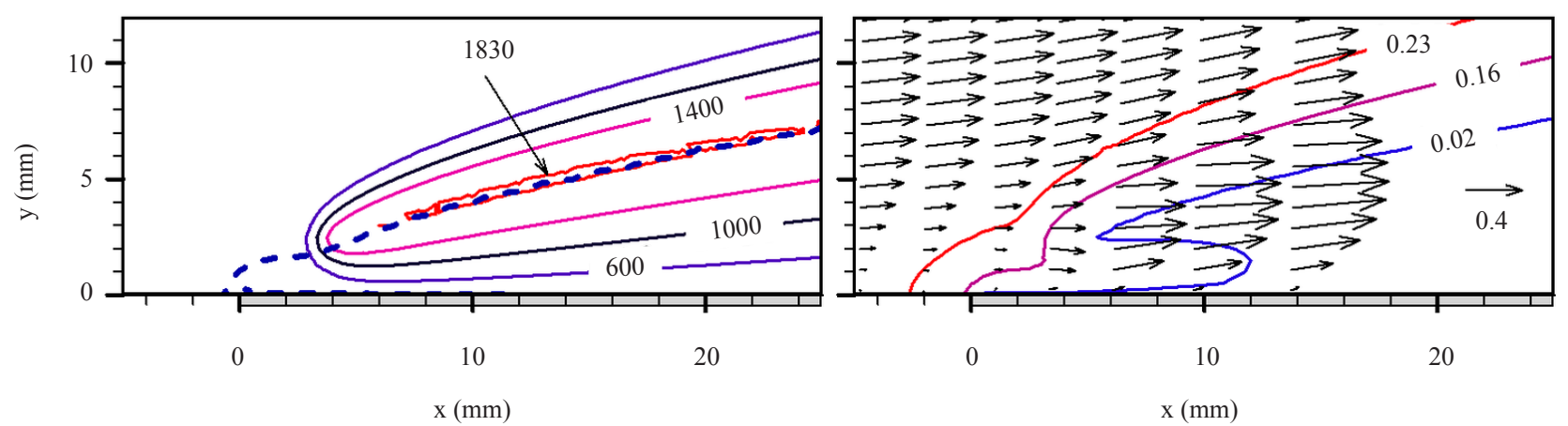

(a)

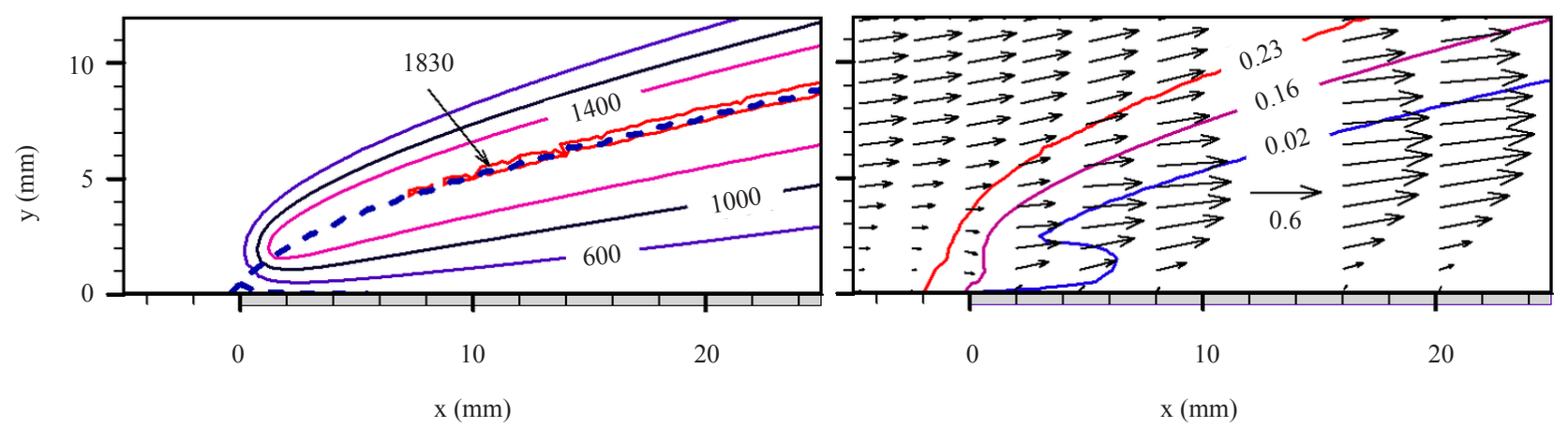

(b)
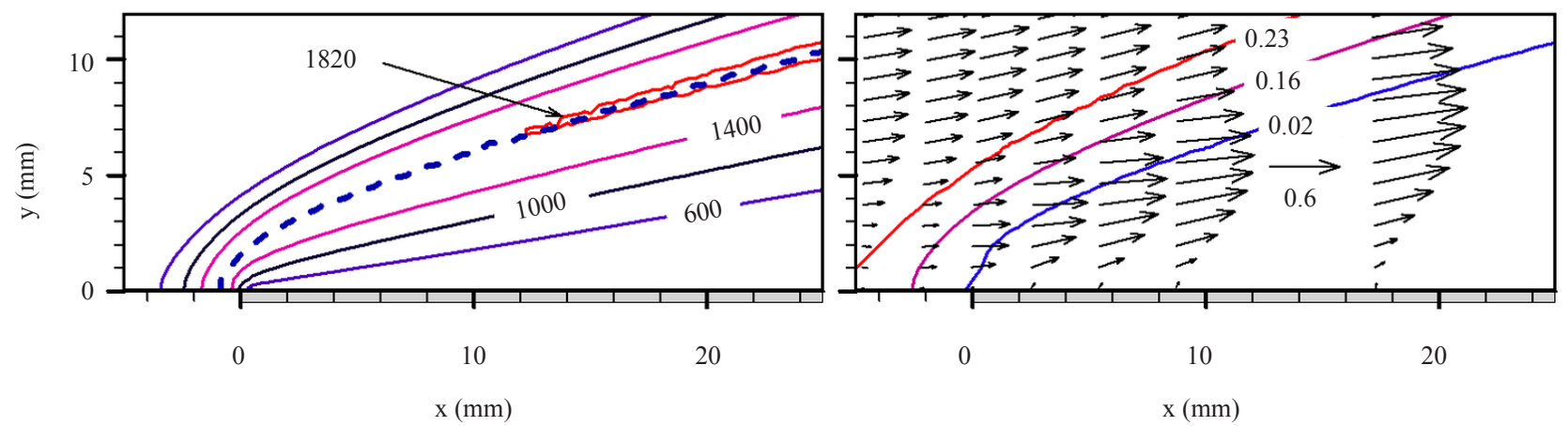

(c)

Figure 8. Contours of temperature along with contour line of $\phi=1$ (dashed line) (left) and mass fraction of oxygen along with mixture velocity vectors (right) for air velocity of $0.4 \mathrm{~m} / \mathrm{s}$, fuel velocity of (a) $0.02 \mathrm{~m} / \mathrm{s}$, (b) $0.03 \mathrm{~m} / \mathrm{s}$ and (c) $0.04 \mathrm{~m} / \mathrm{s}$ and $\mathrm{L}=70 \mathrm{~mm}$

At lower fuel velocities, increased oxygen penetration towards the fuel injector surface is seen by its contour line 
of 0.02, which moves downstream of the leading edge of the fuel injector. The flame stand-off increases as the fuel velocity increases. This aspect is shown by the mixture velocity vectors, which show increased y-component velocity near the fuel injector as the fuel velocity is increased.

Figure 9 shows the contours of the Damköhler number on its left side and contours of mass fractions of $\mathrm{CO}$ and $\mathrm{OH}$ on its right-hand side for the cases presented in Figure 8. As discussed, for higher air velocity cases, due to a reduction in the flow residence time, $\mathrm{Da}=1$ occurs at locations away from the leading edge of the fuel injector. At the position of flame anchoring, contours lines of $\mathrm{Da}=6$ and $\phi=1$ almost overlap. The $\mathrm{CO}$ mass fraction contours indicate the production and consumption of $\mathrm{CO}$ around $\phi=1$ line. Moreover, the contour line corresponding to the $\mathrm{OH}$ mass fraction value of 0.001 (shown as dashed line), indicates the prominent locations of $\mathrm{OH}$ and $\mathrm{CO}$ reactions. $\mathrm{CO}$ oxidation to $\mathrm{CO}_{2}$ that contributes to major heat release, occurs at locations, which coincides with high-temperature zones.

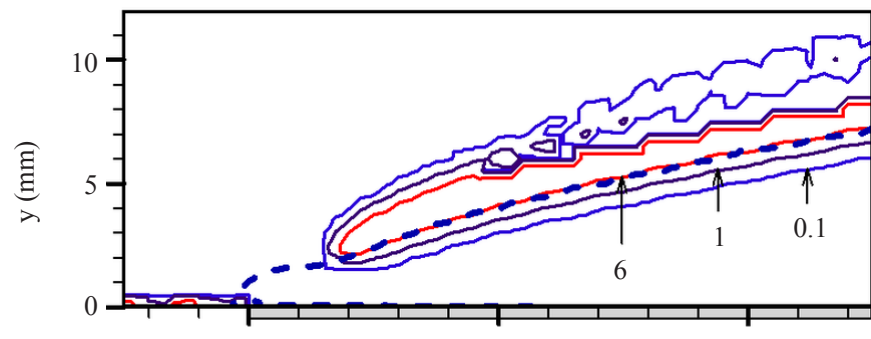

0

10

$\mathrm{x}(\mathrm{mm})$

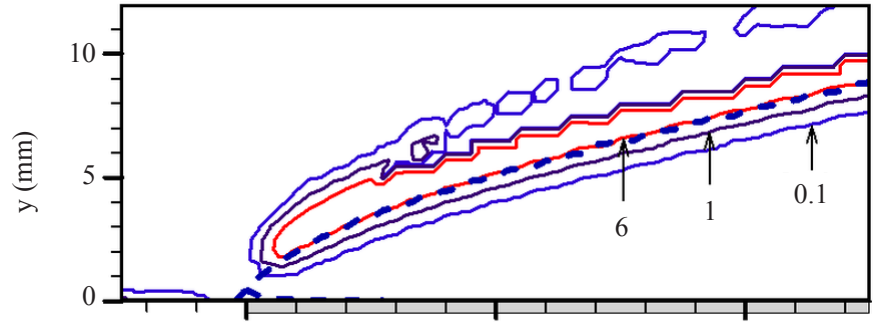

0

10

$\mathrm{x}(\mathrm{mm})$

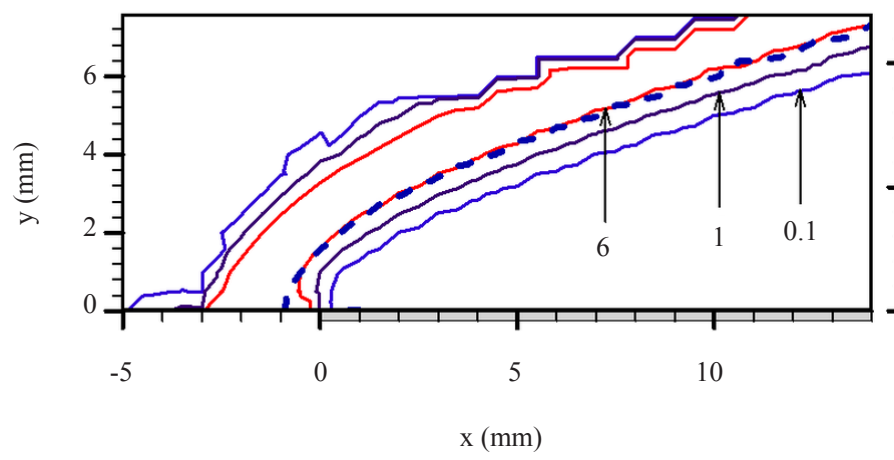

(a)

(b)
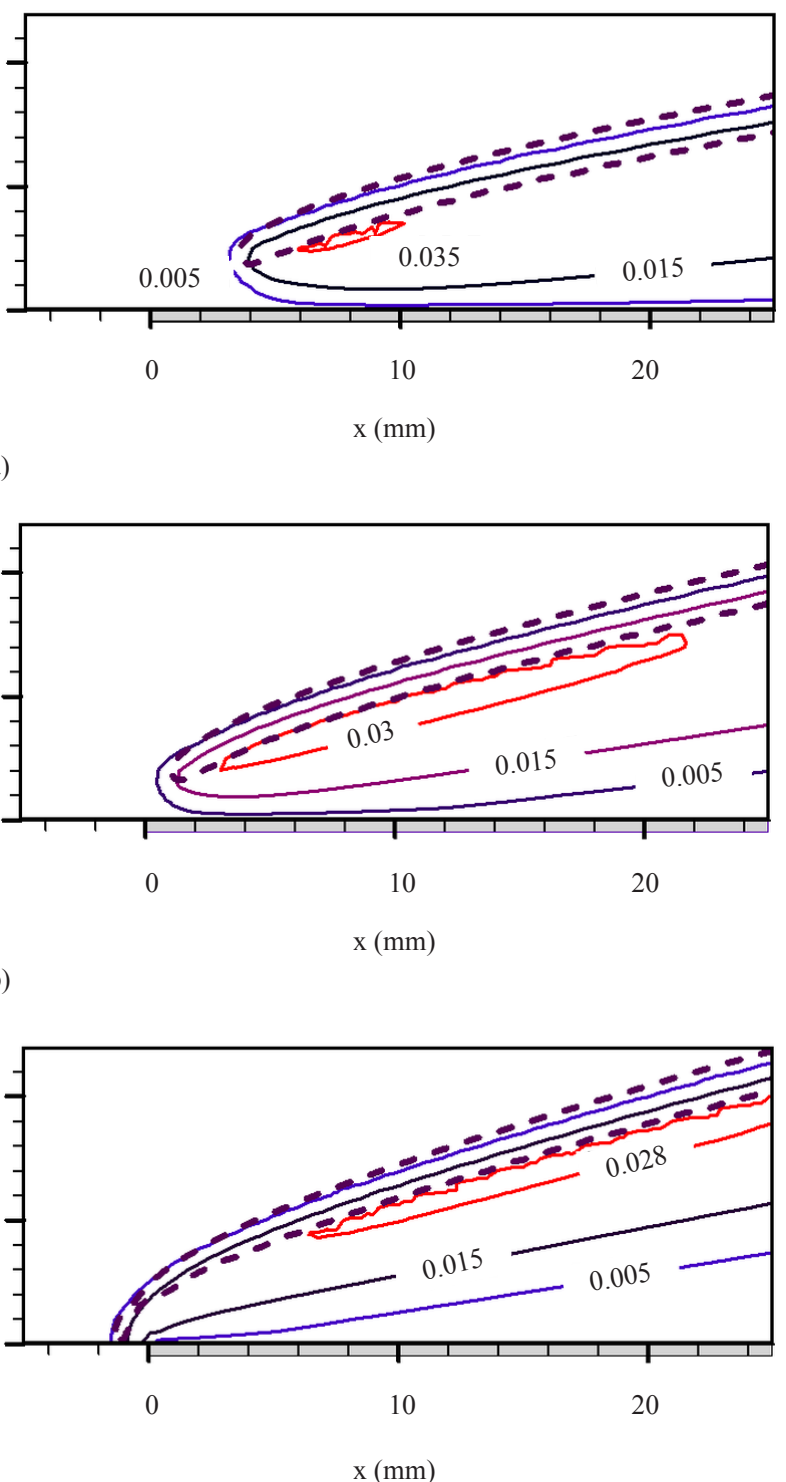

(c)

Figure 9. Contours of Da along with contour line of $\phi=1$ (dashed line) (left)

and mass fraction of $\mathrm{CO}$ along with contour line of mass fraction of $\mathrm{OH}=0.001$ (dashed line) (right) for air velocity of $0.4 \mathrm{~m} / \mathrm{s}$, fuel velocity of (a) $0.02 \mathrm{~m} / \mathrm{s}$, (b) $0.03 \mathrm{~m} / \mathrm{s}$ and (c) $0.04 \mathrm{~m} / \mathrm{s}$ and $\mathrm{L}=70 \mathrm{~mm}$ 
Figure 10 presents the contours of net reaction rates of $\mathrm{CH}_{4}$ along with diffusion velocity vectors of methane in its left-hand side. It is apparent that at lower fuel velocities of $0.02 \mathrm{~m} / \mathrm{s}$ and $0.03 \mathrm{~m} / \mathrm{s}$, the reaction zone has moved downstream of the leading edge of the fuel injector. Even though fuel and oxygen are available at stoichiometric proportions, due to lower residence time, reaction zones form away from the leading edge of the fuel injector, where the chemical time matches the flow time $(\mathrm{Da}=1)$. The diffusion velocity of methane shows that at lower fuel velocities, diffusion of methane occurs only in the region, where a flame zone has been formed, and that the flame sustains as diffusion-controlled flame after the initial premixing. As mentioned earlier, the Soret diffusion is quite stronger when compared to the ordinary diffusion, especially for lighter species such as methane. The net reaction rate of $\mathrm{OH}$, shown on the right side of Figure 10, clearly shows the two-zone consumption of $\mathrm{OH}$. In the inner zone, it is consumed to form $\mathrm{H}_{2} \mathrm{O}$ and in the outer, it reacts with $\mathrm{CO}$ to form $\mathrm{CO}_{2}$. The reaction zones move upstream as the fuel velocity is decreased.

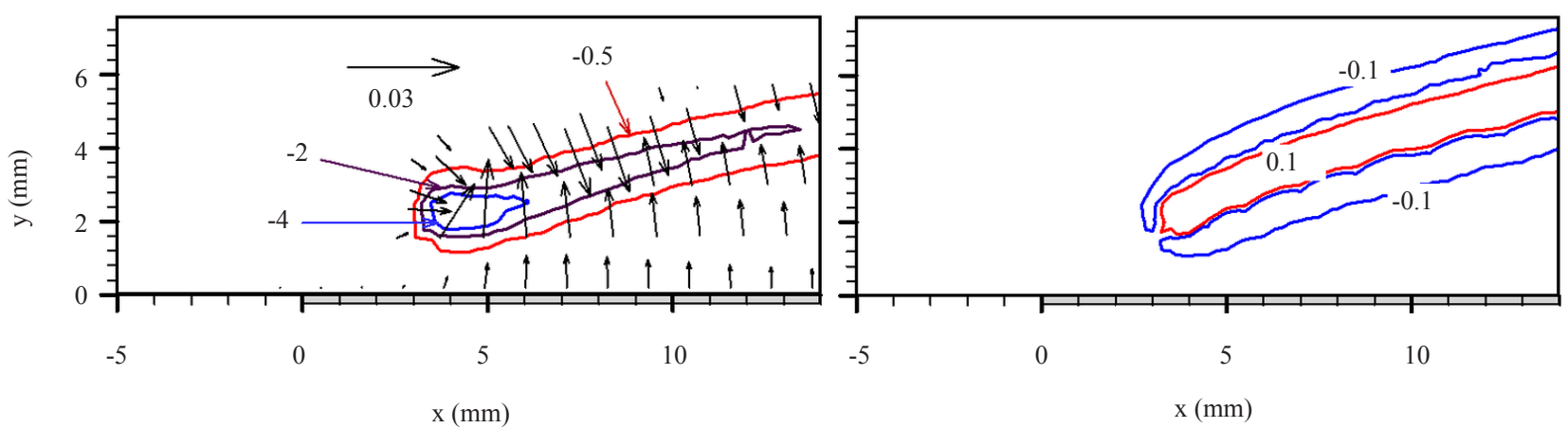

(a)
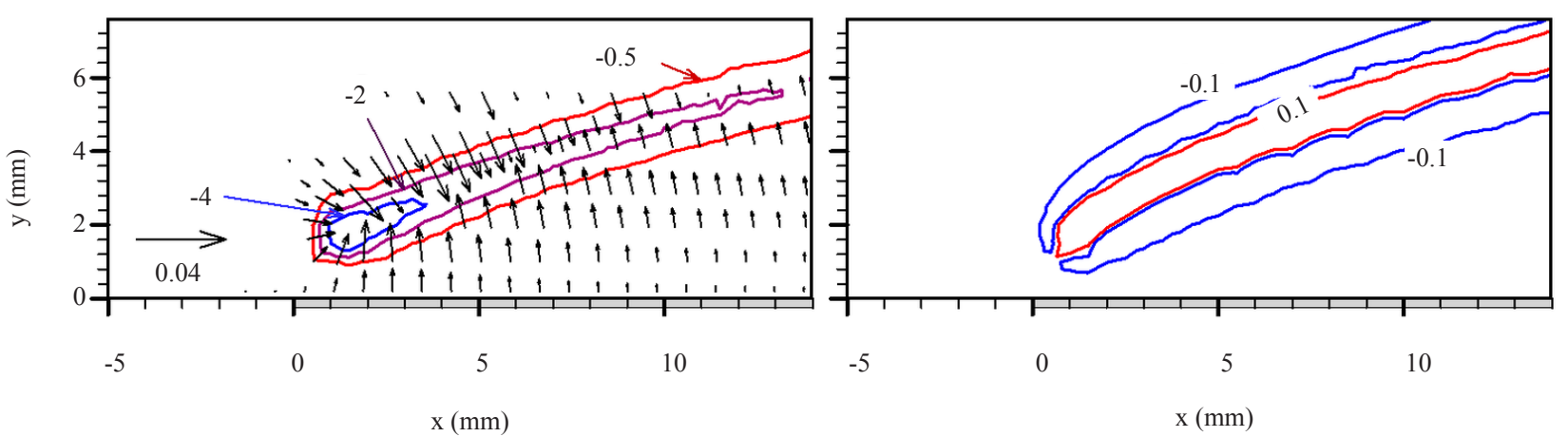

(b)
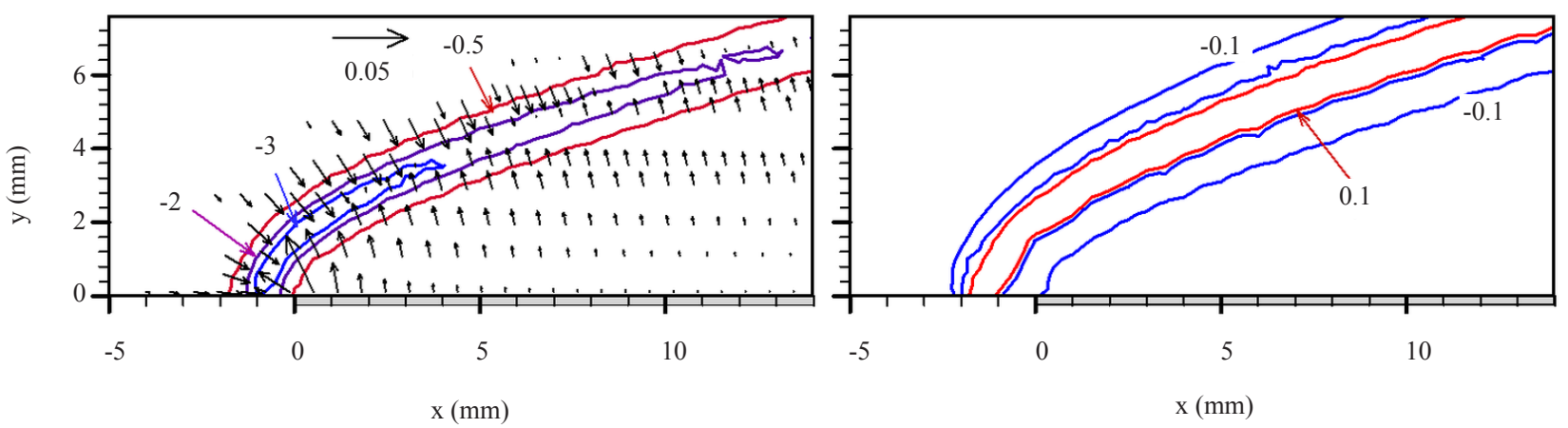

(c)

Figure 10. Contours of NRR of methane along with its diffusion velocity vectors (left) and NRR of $\mathrm{OH}$ (right) for air velocity of $0.4 \mathrm{~m} / \mathrm{s}$, fuel velocity of (a) $0.02 \mathrm{~m} / \mathrm{s}$, (b) $0.03 \mathrm{~m} / \mathrm{s}$ and (c) $0.04 \mathrm{~m} / \mathrm{s}$ and L = $70 \mathrm{~mm}$ 


\subsection{Effect of boundary layer thickness}

In order to determine the effects of boundary layer thickness upstream of the fuel injector on flame characteristics, several conditions have been considered by varying $L$ values $(20 \mathrm{~mm}, 70 \mathrm{~mm}, 100 \mathrm{~mm}, 150 \mathrm{~mm})$ and considering various fuel and air velocities. Figure 11 shows the temperature contours along with $\phi=1$ contour line on its left and oxygen mass fraction contours and mixture velocity vector on its right for the cases where plate stabilized flames form for the value of L between $20 \mathrm{~mm}$ (Figure 11(a)), $70 \mathrm{~mm}$ (Figure 11(b)), and $150 \mathrm{~mm}$ (Figure 11(c)). Here, the fuel velocity is fixed as $0.04 \mathrm{~m} / \mathrm{s}$ and air velocity is kept as $0.2 \mathrm{~m} / \mathrm{s}$. It is apparent from Figure 11 that for all the considered values of $\mathrm{L}$, the flame anchoring position, temperature field, oxygen distribution, and flow field remain almost similar. The maximum temperature in the domain is nearly equal to each other for all the cases and is around 1,830 K.

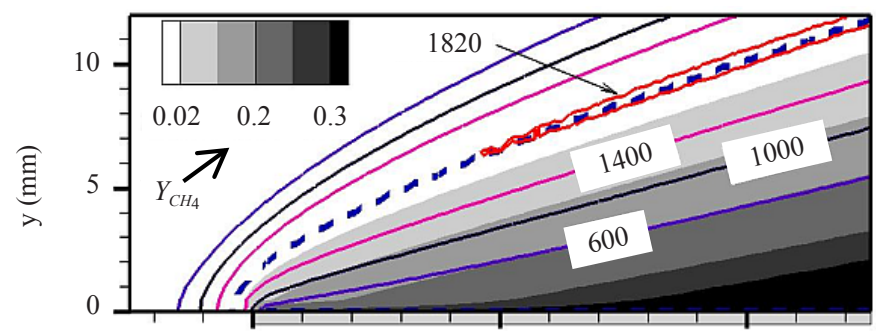

0

10

$\mathrm{x}(\mathrm{mm})$

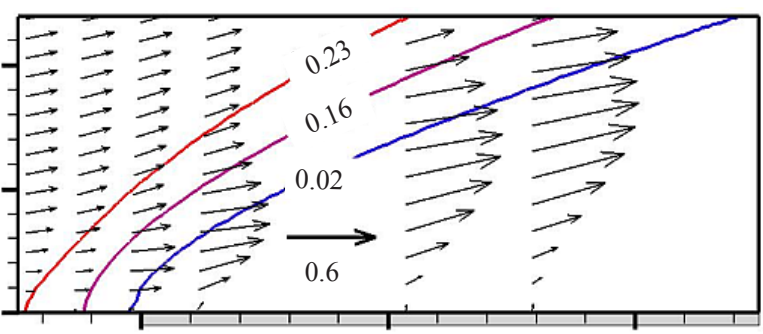

0

10

$\mathrm{x}(\mathrm{mm})$

(a)
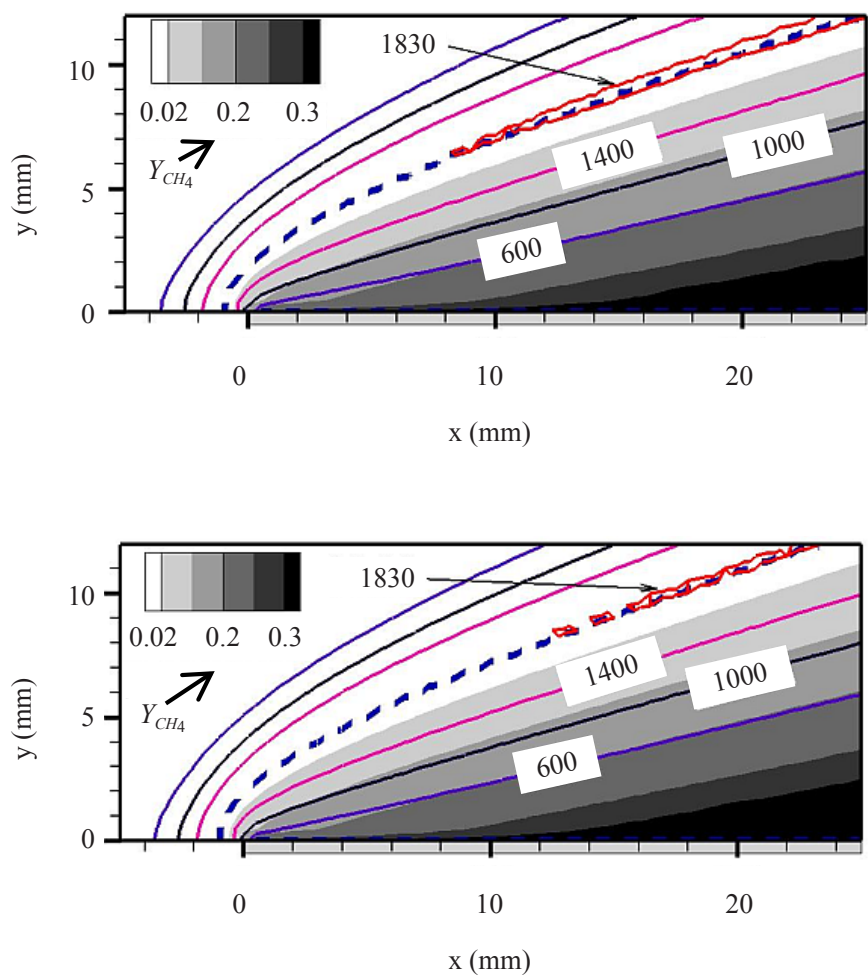

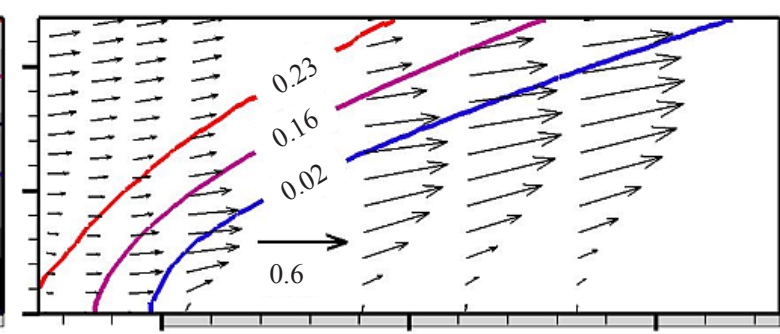

0

10

20

(b)

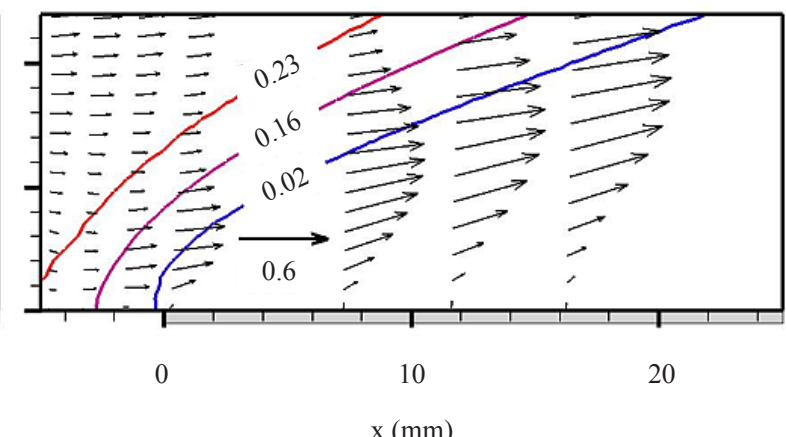

(c)

Figure 11. Contours of temperature (lines) and mass fraction of methane (flooded) along with contour line of $\phi=1$ (dashed line) (left) and mass fraction of oxygen along with mixture velocity vectors (right) for air velocity of $0.2 \mathrm{~m} / \mathrm{s}$, fuel velocity of $0.04 \mathrm{~m} / \mathrm{s}$ and $\mathrm{L}=$ (a) $20 \mathrm{~mm}$, (b) $70 \mathrm{~mm}$ and (c) $150 \mathrm{~mm}$ 

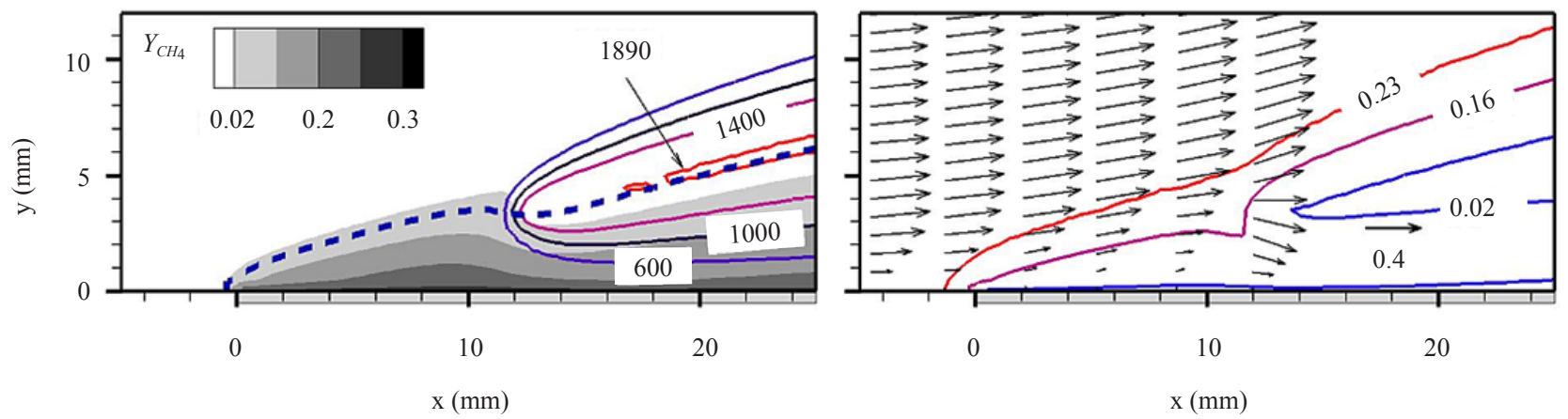

(a)
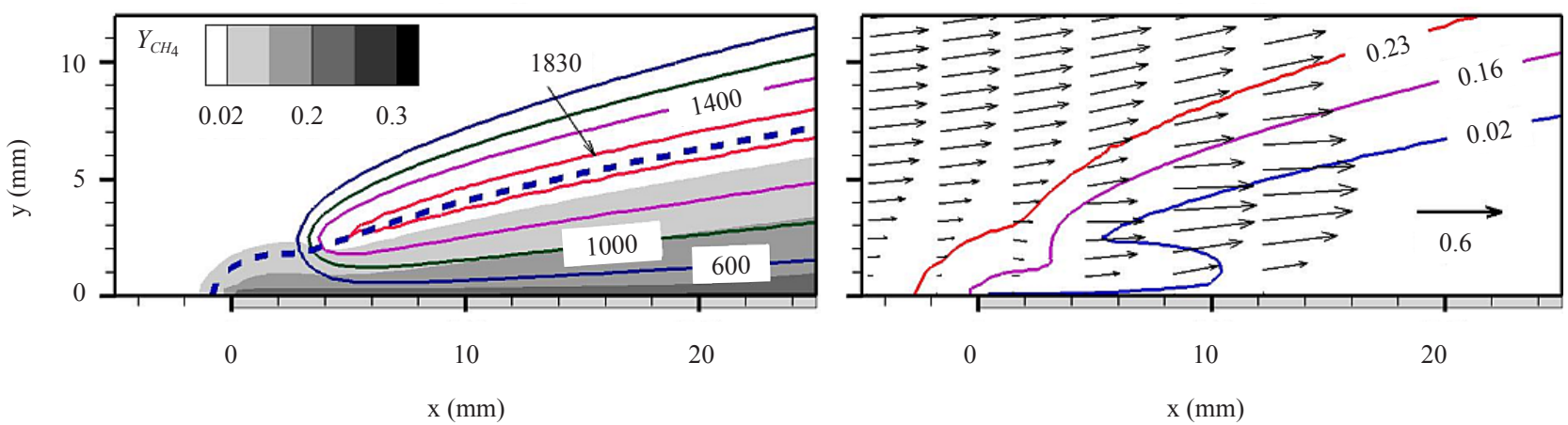

(b)
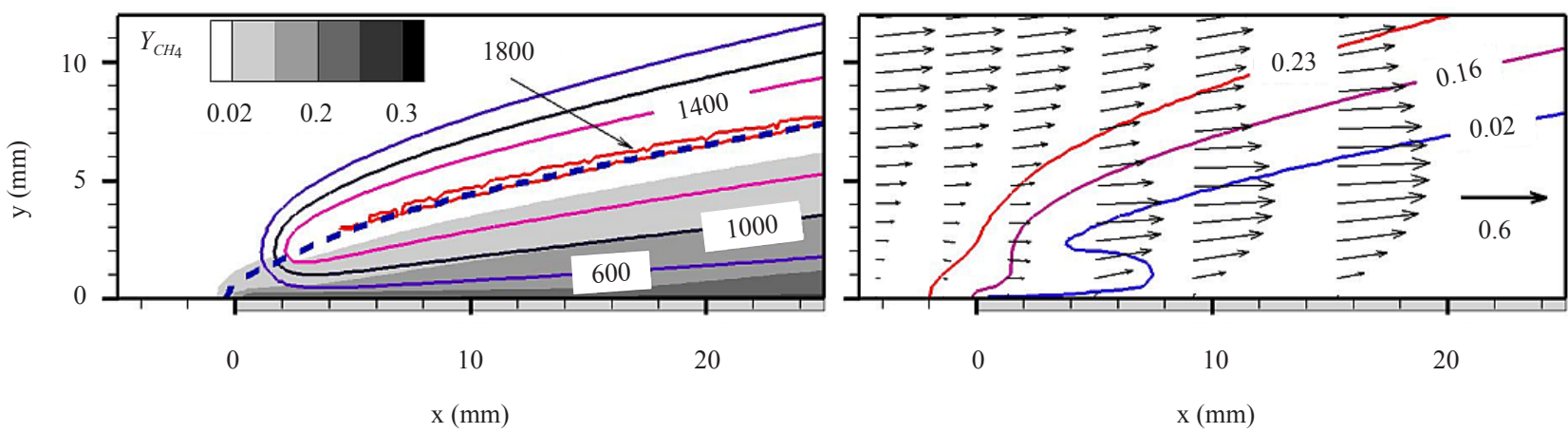

(c)

Figure 12. Contours of temperature (lines) and mass fraction of methane (flooded) along with contour line of $\phi=1$ (dashed line) (left) and mass fraction of oxygen along with mixture velocity vectors (right) for air velocity of $0.4 \mathrm{~m} / \mathrm{s}$, fuel velocity of $0.02 \mathrm{~m} / \mathrm{s}$ and $\mathrm{L}=$ (a) $20 \mathrm{~mm}$, (b) $70 \mathrm{~mm}$, and (c) $150 \mathrm{~mm}$

However, different trends are observed at a lower fuel velocity of $0.02 \mathrm{~m} / \mathrm{s}$ and a higher air velocity of $0.4 \mathrm{~m} / \mathrm{s}$. These significant differences in these conditions are observed as shown in Figure 12. Figure 12 presents the isotherms (left) and the contours of oxygen mass fraction along with the flow field (right) for this case considering $\mathrm{L}=20 \mathrm{~mm}, 70$ $\mathrm{mm}$, and $150 \mathrm{~mm}$. It is apparent that for $\mathrm{L}=20 \mathrm{~mm}$ (Figure 12(a)), the flame has moved downstream from the leading edge of the fuel injector for this fuel and air velocity. With an increase in $\mathrm{L}$ value to $70 \mathrm{~mm}$ and then to $150 \mathrm{~mm}$ the flame moves upstream and anchors closer to the leading edge of the fuel injector. For this low fuel velocity, the transport of oxygen from the air stream towards the fuel stream and the behavior of mixing is critical in determining the flame characteristics. As L increases, the initial boundary layer thickness just upstream of the fuel injector also increases. This decreases in the normal gradient of $\mathrm{x}$-velocity or strain rate in the vicinity of the plate which in turn determines the flame anchoring location as it depends on the strain rate at that position. The strain rate is generally defined as the first gradient of velocity. In the present case, the velocity is dominant in the $\mathrm{x}$-direction, and therefore the gradient of $\mathrm{x}$-velocity 
is defined as the strain rate. As the strain rate of the flow near the fuel injector increases and attains a critical value, the flame is locally extinguished. Further, the flame anchors at a location, where the strain rate is lower than the critical value. Therefore, as the strain rate decreases with increasing $\mathrm{L}$, the flame is able to anchor near that location. In the previous case (Figure 11), the air velocity has been lower and the fuel velocity has been higher than in the present case. There, the fuel transport to the flame zone determined the flame anchoring and the effect of L has not been significant. It is further observed that the flame temperature is higher for $\mathrm{L}=20 \mathrm{~mm}$, due to notable partial premixing happening in that case. The flame stand-off is also the lowest for this case. The effect of L depends upon the pair of fuel and air velocities. The flame lifts from the plate and moves off the leading edge before blowing off from the computational domain at a critical velocity that is dependent on the value of $\mathrm{L}$.

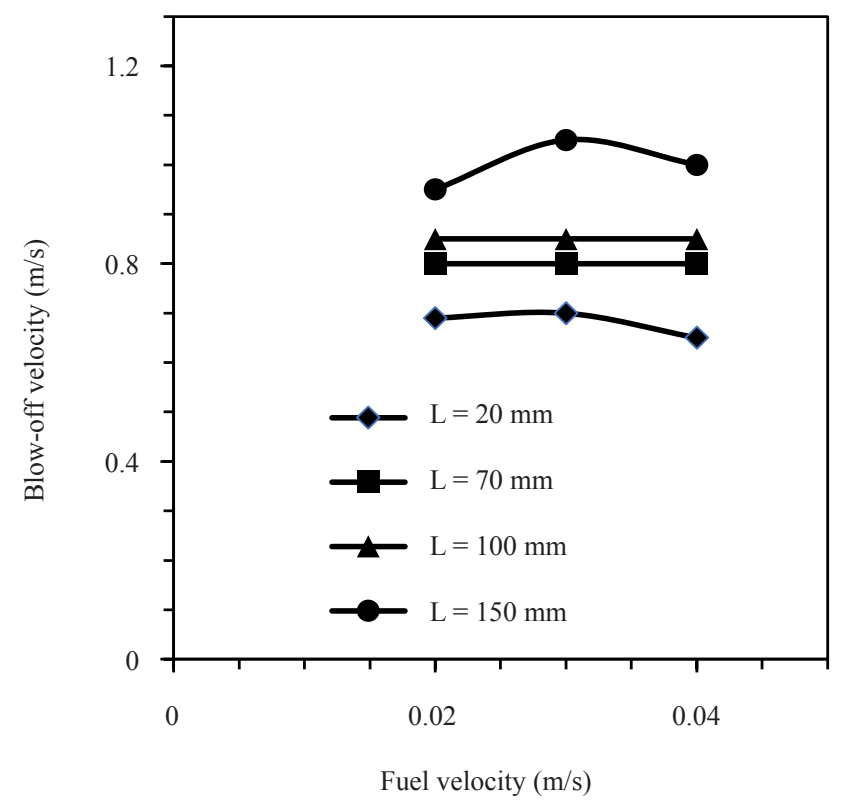

Figure 13. Effect of $\mathrm{L}$ on the blow-off velocity for different fuel injection velocities

Figure 13 presents the effect of L on the blow-off velocity at different fuel velocities and has an uncertainty of $\pm 0.05 \mathrm{~m} / \mathrm{s}$, dependent on the way the air velocity has been incremented in the numerical simulations. It is apparent that blow-off velocity increases as $\mathrm{L}$ is increased, irrespective of the fuel velocities and it can be concluded that for a given $\mathrm{L}$ value, the blow-off velocity is independent of fuel velocity.

This is because of the observation that the flame sustains as a lifted flame (non-anchored near the leading edge of the fuel injector) and blows off the domain at a critical air velocity. Based on the location of the leading flame edge of the lifted flame, a blow-off occurs at a given air velocity. As the flame is anchored closer to the leading edge of the fuel injector at a higher L value, its leading flame edge before the blow-off is expected to the closer to the leading edge of the fuel injector, and therefore, it blows off at a higher air velocity.

\subsection{Effect of fuel}

Even though the only fuel component in biogas is methane, due to the presence of $\mathrm{CO}_{2}$, its characteristics are different from those of pure methane. Keeping the burner configuration, air velocity, and the power rating the same, a comparison between biogas and methane flames is presented here.

Air velocity is chosen as $0.4 \mathrm{~m} / \mathrm{s}$ and the fuel stream velocity for biogas is kept as $0.04 \mathrm{~m} / \mathrm{s}$. For the methane alone case, a fuel velocity of $0.022 \mathrm{~m} / \mathrm{s}$ is selected to have the same power rating. Figure 14 presents the isotherms (left) and oxygen mass fraction contours along with flow field (right) for biogas flame (Figure 14(a)) and methane flame (Figure 
14(b)). Due to the presence of radiation absorption species, $\mathrm{CO}_{2}$, the biogas flame has a lower temperature (by around $100 \mathrm{~K}$ ) than the methane flame of the same power output. Similarly, the flame stand-off is higher for the biogas flame as indicated by flow-field, isotherms, and oxygen mass fraction contours. Due to lower flame temperature, the overshoot velocity magnitude is lower for the biogas flame.
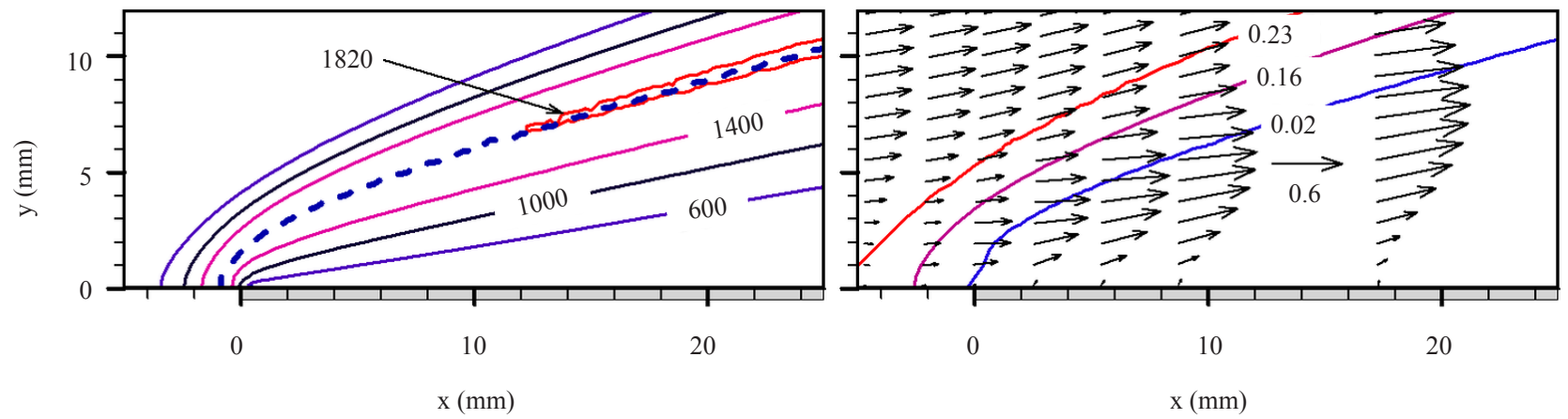

(a)
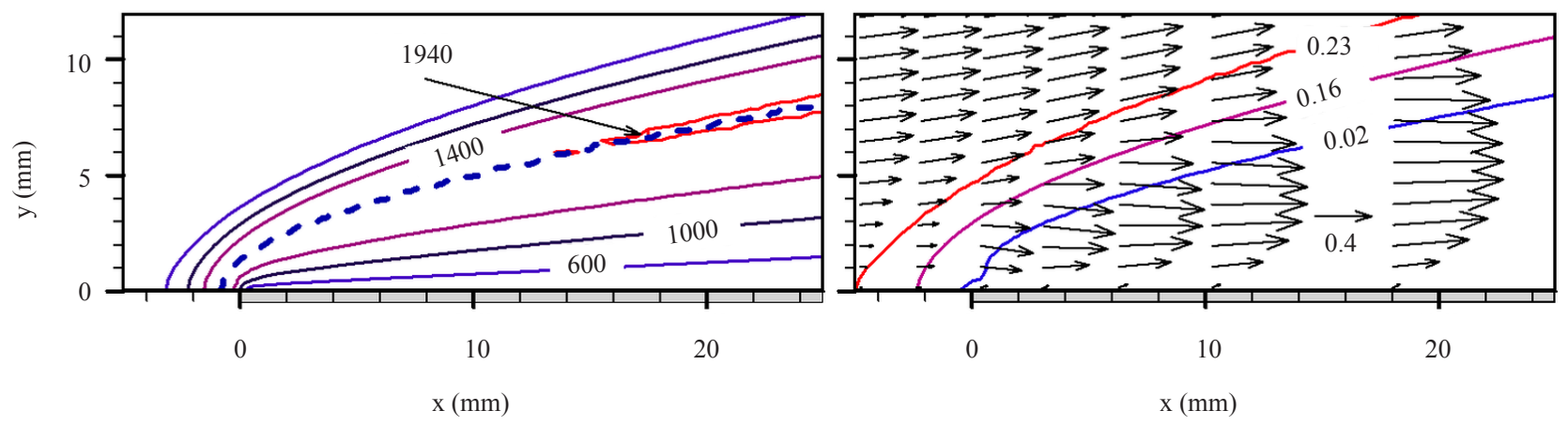

(b)

Figure 14. Contours of temperature along with contour line of $\phi=1$ (dashed line) (left) and mass fraction of oxygen along with mixture velocity vectors (right) for air velocity of $0.4 \mathrm{~m} / \mathrm{s}$, $\mathrm{L}=70 \mathrm{~mm}$, for (a) biogas with a velocity of $0.04 \mathrm{~m} / \mathrm{s}$ and (b) methane with a velocity of $0.022 \mathrm{~m} / \mathrm{s}$

Contours of Da and CO shown in Figure 15 indicate differences mainly in the flame stand-off as clearly shown by the $\phi=1$ contour line (Figure 15, left) and CO contour lines (Figure 15, right). Other features remain common between the two fuels. CO concentration is slightly higher for the methane flame as shown in Figure 15(b). The differences in the $\mathrm{CO}_{2}$ dissociation rate, as well as the differences in the water gas shift reaction rates, form the reason for these trends. Due to a higher flame temperature, the methane reaction rate is expected to be higher. This is shown in Figure 16 (left column). Further, the maximum consumption rate of methane is concentrated much closer to the leading edge of the fuel injector for the methane flame as shown in the left side of Figure 16(b).

As a result, $\mathrm{CO}$ is seen to be spread closer to the leading edge of the fuel injector plate for the methane flame as compared to that of the biogas flame (Figure 15, right). As far as the consumption zones of OH are concerned, apart from the stand-off, the other notable difference is that the $\mathrm{OH}$ consumption zone is slightly wider for the methane flame as shown in the right side of Figure 16. Diffusion velocity vectors of methane in both methane and biogas flames are quite similar to each other. 


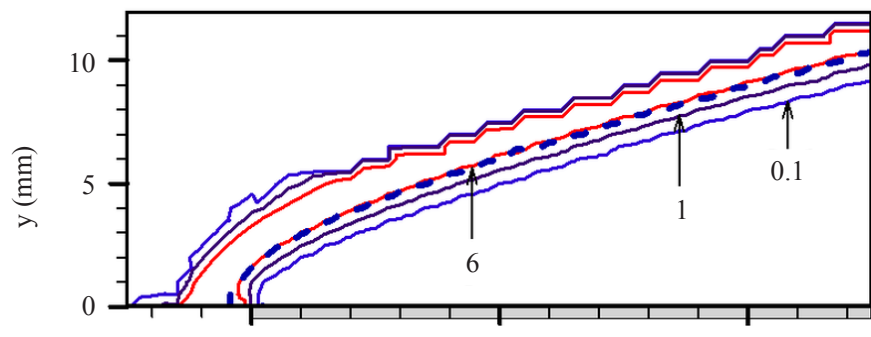

10

$\mathrm{x}(\mathrm{mm})$

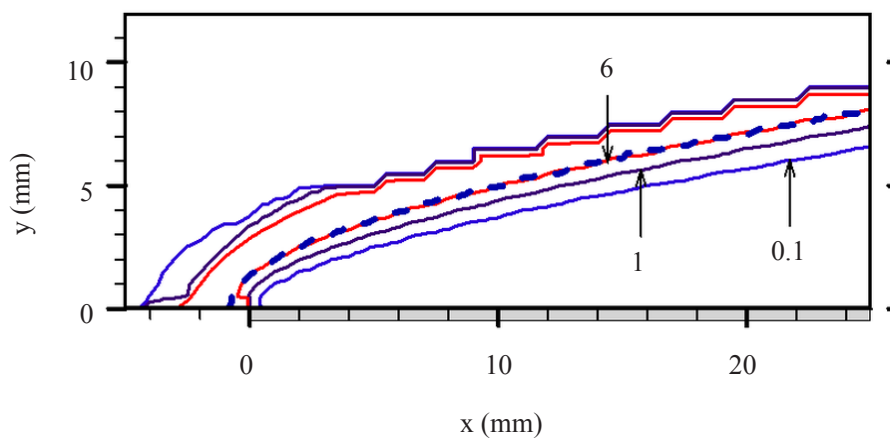

(a)

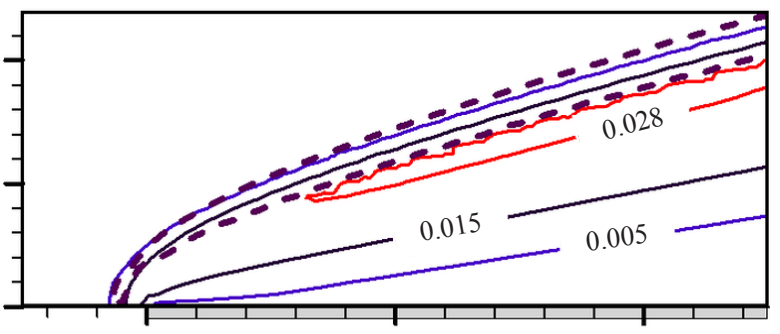

10

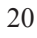

$\mathrm{x}(\mathrm{mm})$
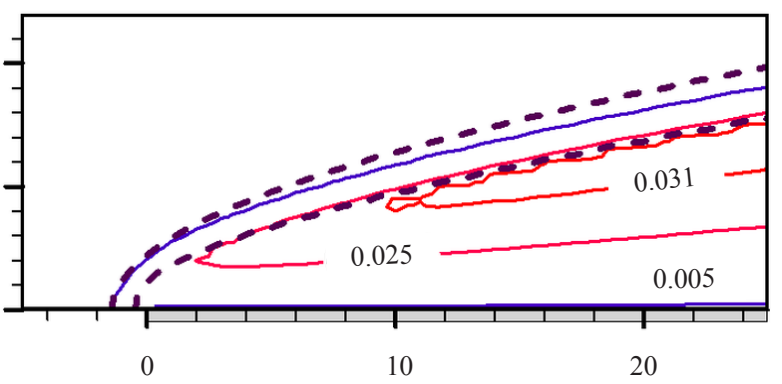

$\mathrm{x}(\mathrm{mm})$

(b)

Figure 15. Contours of Da along with contour line of $\phi=1$ (left) and mass fraction of $\mathrm{CO}$ along with $\mathrm{OH}$ contour line of 0.001 (right) for air velocity of $0.4 \mathrm{~m} / \mathrm{s}$, $\mathrm{L}=70 \mathrm{~mm}$, for (a) biogas with a velocity of $0.04 \mathrm{~m} / \mathrm{s}$ and (b) methane with a velocity of $0.022 \mathrm{~m} / \mathrm{s}$
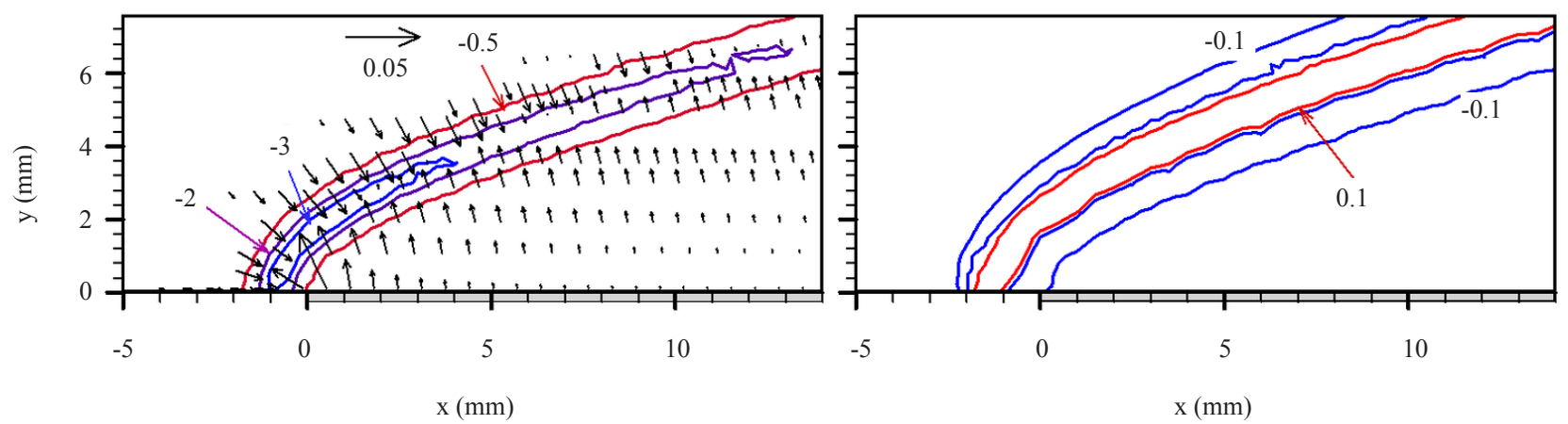

(a)
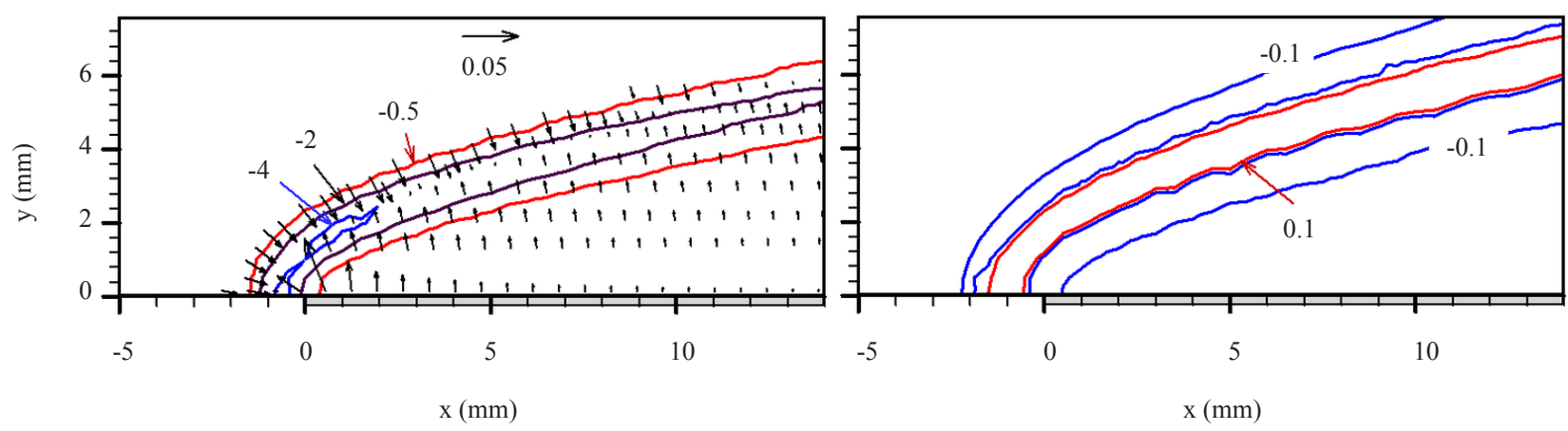

(b)

Figure 16. Contours of NRR of $\mathrm{CH}_{4}$ along with methane diffusion velocity vectors (left) and NRR of $\mathrm{OH}$ (right) for air velocity of $0.4 \mathrm{~m} / \mathrm{s}$, $\mathrm{L}=70 \mathrm{~mm}$, for (a) biogas with a velocity of $0.04 \mathrm{~m} / \mathrm{s}$ and (b) methane with a velocity of $0.022 \mathrm{~m} / \mathrm{s}$ 


\section{Conclusions}

Numerically predicted characteristics of cross-flow non-premixed biogas-air flames are presented systematically. The flow, temperature, velocity, and species mass fraction fields have been used to explain the flame structure. For flames stabilized in the plate region upstream of the fuel injector, the high-temperature isotherms extend beyond the leading edge of the fuel injector into the upstream plate region, thus forming an anchoring point in that region. The stoichiometric equivalence ratio contour line is seen close to the maximum temperature isotherm. The flow is accelerated across the flame zone, producing velocity overshoot in the reactive flow field. The contour line of oxygen mass fraction value of around 0.02 is seen to coincide with the stoichiometric equivalence ratio line. The consumption of $\mathrm{CO}$ is engulfed by the $\mathrm{OH}$ contour lines of 0.001 , contributing to $\mathrm{CO}$ oxidation as well as to the formation of water vapor in two distinct zones. A flame zone forms if the Damköhler number (Da) is greater than or equal to 1, where there is a balance between the flow and the chemical reaction times. The contour line of $\mathrm{Da}=6$ is seen to be closer to the stoichiometric equivalence ratio line. The diffusion velocity of methane is calculated as a sum of concentration gradientbased (ordinary) diffusion and that due to temperature gradient (Soret diffusion). The Soret diffusion is quite stronger when compared to the ordinary diffusion for methane. The consumption of methane is very rapid near the leading edge of the fuel injector, where fuel and fresh oxygen mix to react.

As the air velocity is increased, the flame anchoring point moves from upstream of the leading edge of the fuel injector to a location just downstream of the leading edge of the fuel injector. The contour line of $\phi=1$ cannot show this transition. This flame has characteristics of a flame with a partially premixed kernel initially and that grows as a nonpremixed flame at farther $\mathrm{x}$-locations. As the air velocity is increased, the flame stand-off is seen to decrease. Even in the unanchored flame, the contour line of $\mathrm{Da}=6$ falls much closer to the high-temperature zone indicating that the chemical reaction is at the peak at those locations. The diffusion velocity of methane shows that at higher air velocities, diffusion of methane occurs only in the region, where a flame zone has been formed. This also clearly shows that the flame sustains as a diffusion-controlled flame after the initial premixing. Also, the magnitude of diffusion velocity is seen to increase with an increase in the air velocity. The net reaction rate of $\mathrm{OH}$ clearly shows the two-zone consumption of $\mathrm{OH}$. In the inner zone, it is consumed to form $\mathrm{H}_{2} \mathrm{O}$ and in the outer, it reacts with $\mathrm{CO}$ to form $\mathrm{CO}_{2}$. At a given air velocity, as the fuel velocity is increased, an unanchored flame moves upstream and forms a plate stabilized flame at a particular fuel velocity. The flame stand-off increases as the fuel velocity is increased.

The influence of the length of the plate before the fuel injector (L) is dependent on the values of fuel and air velocities. When the flame is plate stabilized, the characteristics remain almost the same irrespective of the value of L. The flame moves off the leading edge and blows off from the computational domain at a critical air velocity that is dependent on the value of $\mathrm{L}$. The blow-off air velocity increases as $\mathrm{L}$ is increased, irrespective of the fuel velocity. Based on the location of the leading flame edge of the lifted flame, blow-off occurs at a given air velocity.

A comparison of characteristics of methane and biogas flames at the same power rating reveals that because of the presence of radiation absorption species, $\mathrm{CO}_{2}$, the biogas flame has a lower flame temperature (by around $100 \mathrm{~K}$ ) than the methane flame of the same power output. Similarly, the flame stand-off is higher for the biogas flame. Methane flame has a slightly higher overshoot velocity magnitude located below the biogas flame due to the higher injection velocity of biogas for the same power rating.

\section{Acknowledgements}

The authors would like to thank P. G. Senapathy centre for computing resources, and IIT Madras for providing the computational facility required for the present work.

\section{Conflict of interest}

The authors declare no conflict of interest. 


\section{References}

[1] H. Emmons, "The film combustion of liquid fuel," Journal of Applied Mathematics and Mechanics, vol. 36, pp. 60-71, 1956.

[2] Y. Mori, "Buoyancy effects in forced laminar convection flow over a horizontal flat plate," ASME Journal of Heat Transfer, vol. 83, no. 4, pp. 479-482, 1961.

[3] E. M. Sparrow and W. J. Minkowycz, "Buoyancy effects on horizontal boundary-layer flow and heat transfer," International Journal of Heat and Mass Transfer, vol. 5, pp. 505-511, 1962.

[4] A. Q. Eschenroeder, "Combustion in the boundary layer on a porous surface," Journal of the Aerospace Sciences, vol. 27, no. 12, pp. 901-906, 1960.

[5] P. A. Libby and M. Pierucci, "Laminar boundary layer with hydrogen injection including multicomponent diffusion," AIAA Journal, vol. 2, no. 12, pp. 2118-2126, 1964.

[6] G. T. Sergeev, B. M. Smolsky, and L. I. Tarasevich, "Heat and mass transfer for reaction of injected fluid with external oxygen flow," International Journal of Heat and Mass Transfer, vol. 13, pp. 1215-1224, 1970.

[7] Y. Nakagwa, N. Nishiwaki, and M. Hirata, "Effect of combustion on a laminar boundary layer," Symposium (International) on Combustion, vol. 31, no. 1, pp. 813-819, 1971.

[8] K. Shinzo and Y. Katsuhiro, "Theoretical investigation on laminar boundary layer with combustion on a flat plate," International Journal of Heat and Mass Transfer, vol. 16, pp. 1215-1229, 1973.

[9] M. Lavid and A. L. Berlad, "Gravitational effects on chemically reacting laminar boundary layer flows over a horizontal flat plate," Symposium (International) on Combustion, vol. 16, no. 1, pp. 1557-1568, 1977.

[10] N. Peters, "Analysis of a laminar flat plate boundary-layer diffusion flame," International Journal of Heat and Mass Transfer, vol. 18, pp. 385-393, 1976.

[11] P. A. Libby and C. Economos, "A flame zone model for chemical reaction in a laminar boundary layer with application to the injection of hydrogen-oxygen mixtures," International Journal of Heat and Mass Transfer, vol. 6, pp. 113-128, 1963.

[12] T. Hirano and Y. Kanno, "Aerodynamics and thermal structures of the laminar boundary layer over a flat plate with a diffusion flame," Symposium (International) on Combustion, vol. 14, no. 1, pp. 391-398, 1973.

[13] T. Hirano and M. Kinoshita, "Gas velocity and temperature profiles of a diffusion flame stabilized in the stream over liquid pool” Symposium (International) on Combustion, vol. 15, no. 1, pp. 379-381, 1975.

[14] A. Ramachandra and B. N. Raghunandan, "Investigations on the stability and extinction of a laminar diffusion flame over a porous flat plate," Combustion Science and Technology, vol. 36, no. 3-4, pp. 109-121, 1984.

[15] T. Ueda, A. Ooshima, N. Saito, and M. Mizomoto, "Aerodynamic structure of a laminar boundary layer diffusion flame over a horizontal flat plate: 2nd report, experimental analysis," Transactions of the Japan Society of Mechanical Engineers Series B, vol. 56, no. 531, pp. 3501-3507, 1991.

[16] J. S. Ha, S. H. Shim, and H. D. Shin, "Boundary layer diffusion flame over a flat plate in the presence and absence of flow separation," Combustion Science and Technology, vol. 75, pp. 241-260, 1991.

[17] J. L. Torero, L. Bonneau, J. M. Most, and P. Joulain, "The effect of gravity on a laminar diffusion flame established over a horizontal flat plate," Symposium (International) on Combustion, vol. 25, no. 1, pp. 1701-1709, 1994.

[18] C.-P. Mao, H. Kodama, and A. C. Fernandez-Pello, "Convective structure of a diffusion flame over a flat combustible surfacel," Combustion and Flame, vol. 57. pp. 209-236, 1984.

[19] T. Ueda and M. Mizomoto, "Aerodynamic structure of a flat plate laminar boundary layer with diffusion flame," Computational Mechanics, vol. 5, pp. 263-272, 1989.

[20] V. Raghavan, A. S. Rangwala, and J. L. Torero, "Laminar flame propagation on a horizontal fuel surface: Verification of classical Emmons solution," Combustion Theory and Modelling, vol. 3, no. 1, pp. 121-141, 2009.

[21] E. D. Gopalakrishnan and V. Raghavan, "Numerical investigation of laminar diffusion flames established on a horizontal flat plate in a parallel air stream," International Journal of Spray and Combustion Dynamics, vol. 3, no. 2, pp. 69-98, 2011.

[22] D. Andriani, A. Wresta, T. D. Atmaja, and A. Saepudin, "A review on optimization production and upgrading biogas through $\mathrm{CO}_{2}$ removal using various techniques," Applied Biochemistry and Biotechnology, vol. 172, pp. 1909-1928, 2014.

[23] U. K. Imran, M. H. D. Othman, H. Hashim, T. Matsuura, A. F. Rezaei-DashtArzhandi, and I. Wan Azelee, "Biogas as a renewable energy fuel-A review of biogas upgrading utilization and storage," Energy Conversion and Management, vol. 150, pp. 277-294, 2017.

[24] E. Ryckebosh, M. Drouillon, and H. Vervaeren, "Techniques for transformation of biogas to biomethane," Biomass 
and Bioenergy, vol. 35, no. 5, pp. 1633-1645, 2011.

[25] S. Rasi, A. Veijanen, and J. Rintala, “Trace compounds of biogas from different biogas production plants," Energy, vol. 32, no. 8, pp. 1375-1380, 2007.

[26] H.-C. Shin, J.-W. Park, J. Park, and H.-C. Song, "Removal characteristics of trace compounds of landfill gas by activated carbon adsorption,” Environmental Pollution, vol. 119, pp. 227-236, 2002.

[27] R. J. Spiegel and J. L. Preston, "Test results for fuel cell operation on anaerobic digester gas," Journal of Power Sources, vol. 86, no. 1-2, pp. 283-308, 2000.

[28] R. J. Spiegel and J. L. Preston, "Technical assessment of fuel cell operation on anaerobic digester gas at the yonkers, NY, wastewater treatment plant," Waste Management, vol. 23, pp. 709-717, 2003.

[29] A. Lock, K. A. Suresh, K. P. Ishwar, and H. Uday, "Suppression of fuel and air stream diluted methane-air partially premixed flames in normal and microgravity," Fire Safety Journal, vol. 43, no. 1, pp. 24-35, 2008.

[30] T. Leung and I. Wierzba, "The effect of hydrogen addition on biogas non-premixed jet flame stability in a coflowing air stream," International Journal of Hydrogen Energy, vol. 33, pp. 3856-3862, 2008.

[31] C.-E. Lee and C.-H. Hwang, "An experimental study on the flame stability of LFG and LFG-mixed fuels," Fuel, vol. 86, no. 5-6, pp. 649-655, 2007.

[32] L. Xiang, H. Chu, F. Ren, and M. Gu, "Numerical analysis of the effect of $\mathrm{CO}_{2}$ on combustion characteristics of laminar premixed methane/air flames," Journal of the Energy Institute, vol. 92, no. 5, pp. 1-15, 2018.

[33] I. E. James, J. H. Kevin, M. Lin, F. Michael, P. Mohamed, and W. Alan, "Effect of $\mathrm{CO}_{2}$ dilution on the structure and emissions from turbulent, non-premixed methane-air jet flames," Journal of the Energy Institute, vol. 90, no. 2, pp. 191-200, 2017.

[34] N. Hinton and R. Stone, "Laminar burning velocity measurements of methane and carbon dioxide mixtures (biogas) over wide ranging temperatures and pressures," Fuel, vol. 116, pp. 743-750, 2014.

[35] B. Galmiche, F. Halter, F. Foucher, P. Dagaut, "Effect of dilution on laminar burning velocity of premixed methane/air flames," Energy \& Fuels, vol. 25, no. 3, pp. 948-954, 2011.

[36] S. Jahangirian, E. Abraham, S. W. Indrek, "Thermal and chemical structure of biogas counterflow diffusion flames," Energy \& Fuels, vol. 23, no. 11, pp. 5312-5321, 2009.

[37] M. Abdelbaki and T. Fouzi, "Numerical investigation of counter-flow diffusion flame of biogas-hydrogen blends: Effects of biogas composition, hydrogen enrichment and scalar dissipation rate on flame structure and emissions," International Journal of Hydrogen Energy, vol. 41, no. 3, pp. 2011-2022, 2016.

[38] M. R. J. Charest, Ö. L. Gülder, and P. T. Clinton Groth, "Numerical and experimental study of soot formation in laminar diffusion flames burning simulated biogas fuels at elevated pressures," Combustion and Flame, vol. 161, pp. 2678-2691, 2014.

[39] R. S. Barlow, A. N. Karpetis, J. H. Frank, and J.-Y. Chen, "Scalar profiles and no formation in laminar opposedflow partially premixed methane/air flames," Combustion and Flame, vol. 127, pp. 2102-2118, 2001.

[40] A. Harish, H. R. Rakesh Ranga, B. Aravindh, V. Raghavan, "Experimental study of the flame characteristics and stability regimes of biogas-air cross flow non-premixed flames," Fuel, vol. 223, pp. 334-343, 2018.

[41] P. K. Shijin, S. Soma Sundaram, V. Raghavan, and V. Babu, "Numerical investigation of laminar cross flow nonpremixed flames in the presence of a bluff-body," Combustion Theory and Modelling, vol. 18, no. 6, pp. 692-710, 2014. 


\section{Appendix A}

The numerical model with kinetics mechanism having 25 species and radiation sub-model has been validated against the experimental data of Hirano and Kanno [12] on methane flame in air cross-flow. Uncorrected temperature profiles at various $\mathrm{x}$-locations are reported in [12]. Temperature has been corrected for radiation and convection losses and the corrected profiles are plotted in Figure A1, along with predicted temperature profiles.

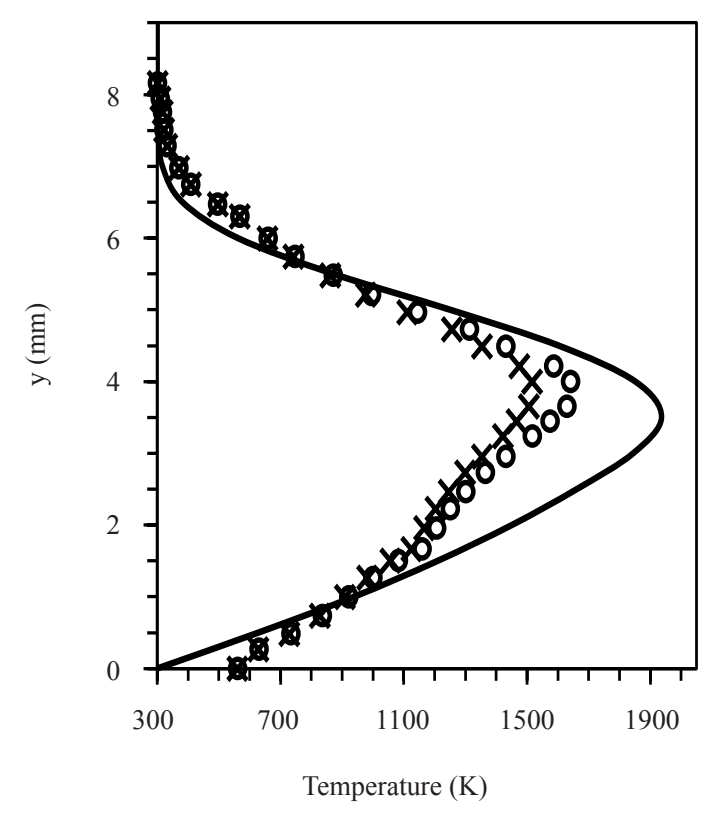

(a)

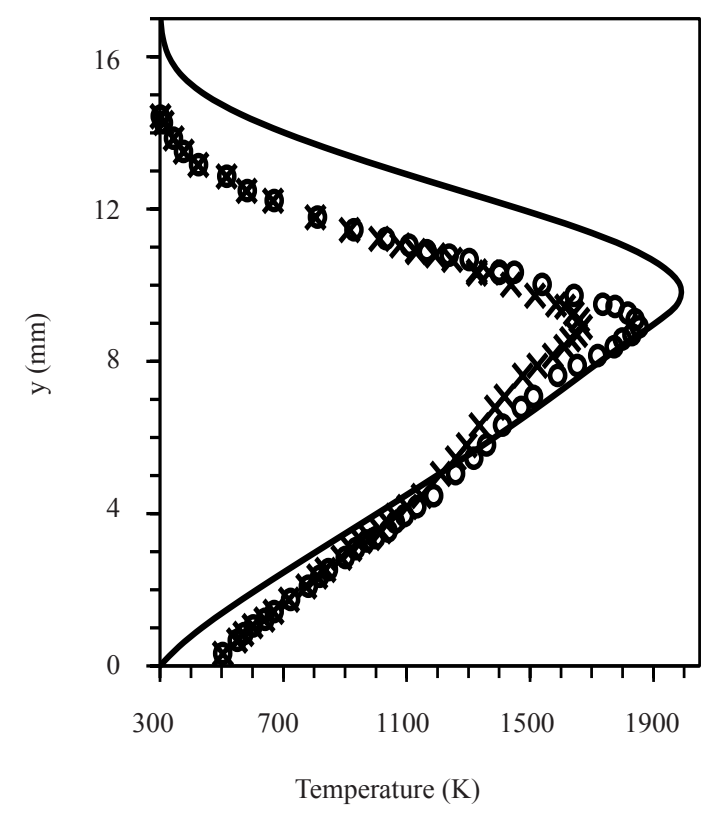

(c)

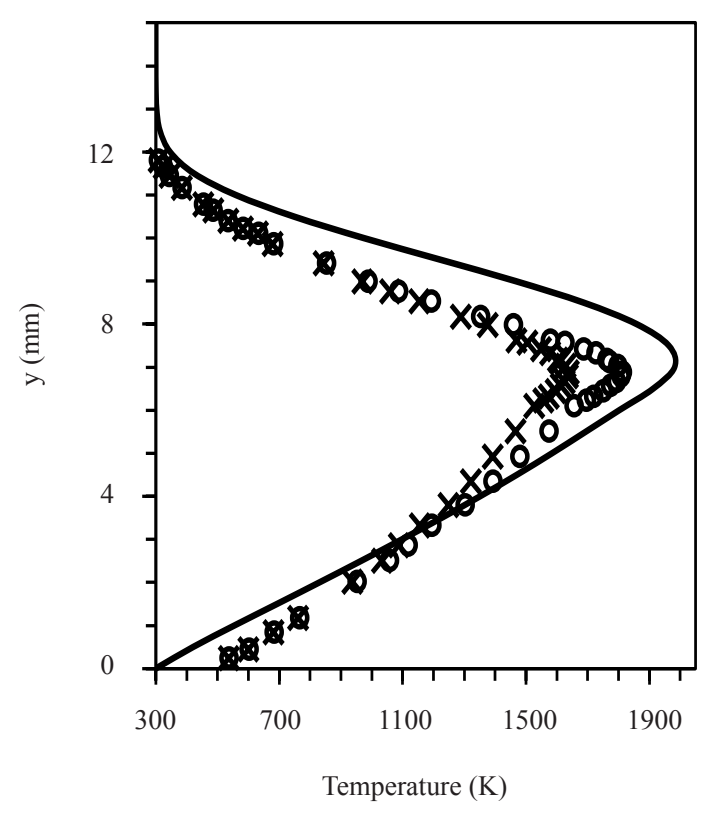

(b)

- Experimental, corrected

Numerical, present

Figure A1. Comparison of predicted temperature profiles with uncorrected and corrected measured profiles of Hirano and Kanno [12] for methane flame in cross-flow air with methane and air velocities of $0.02 \mathrm{~m} / \mathrm{s}$ and $0.65 \mathrm{~m} / \mathrm{s}$,

respectively, at x-locations of (a) $10 \mathrm{~mm}$, (b) $30 \mathrm{~mm}$ and (c) $50 \mathrm{~mm}$ measured from the leading edge of the fuel injector 